\title{
استراتيجية القوة الناعمة في مجابهة الازمات الدولية: الوسائل الدبلوماسية انموذجا
}

\author{
Doi: $10.23918 /$ ilic2020.08 \\ م. يونس طلعت الاباغ \\ أ.م.د محمد وائل القيسي \\ المقدمة
}

أن الازمات الدولية المتلاحقة باتت احد اهم سمات عالم السياسة في هذا العصر الحديث، عصر المعرفة والته والتكنولوجيا

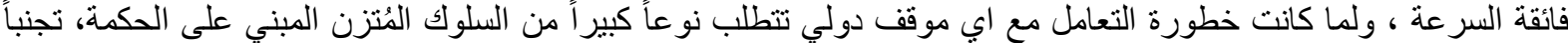

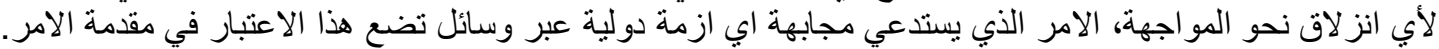

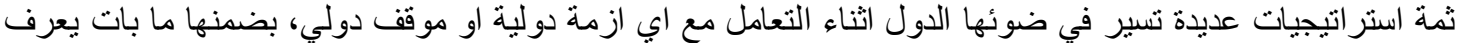

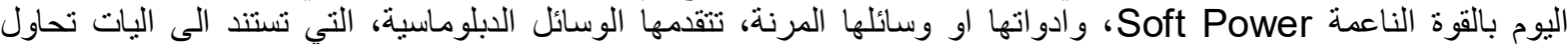

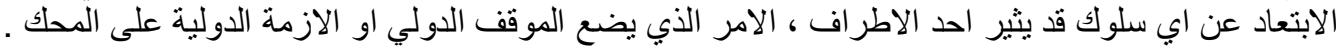

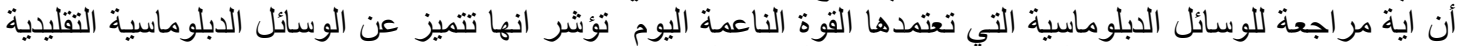

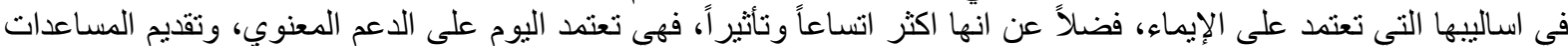

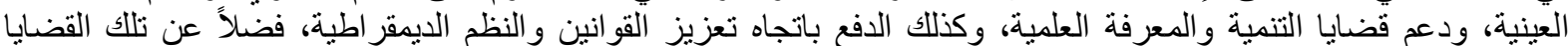

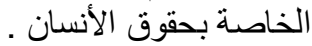

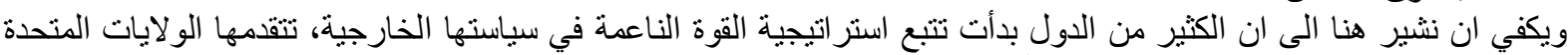

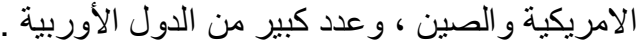
أهمية الدراسة : تثمحور اهمية الدراسة حول أهمية الموضوع أهود ذاته، كون ليس من السهولة مجابهة ازمات عالم اليوم الأكثر

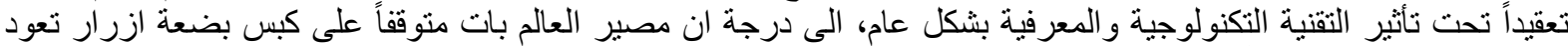

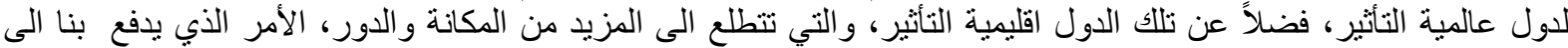

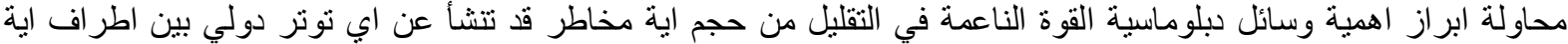

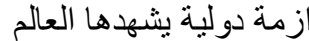

إشكالية الاراسة : حولة حملت الدراسة اشكالية مهمة تتمثل بحدود القدرة التي تستطيع معها الوسائل الدبلوماسية ضمن الية القوة

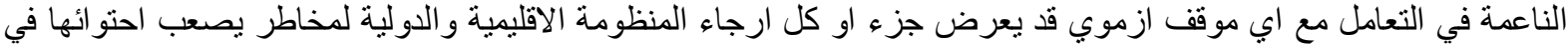
ظل تكنولوجيا عالم اليوم ، فائقة السر عة فئ. فرضية الاراسة :تنطلق الدر اسة من فرضية مفادها الأتي : كلما أحكمت الدول التي تتبع استر اتيجية القوة الناعمة ، استخدام

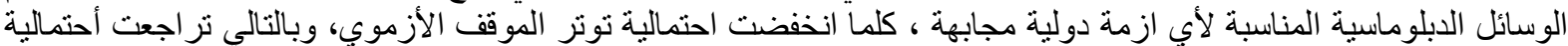

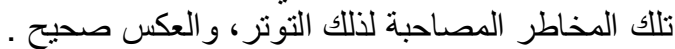

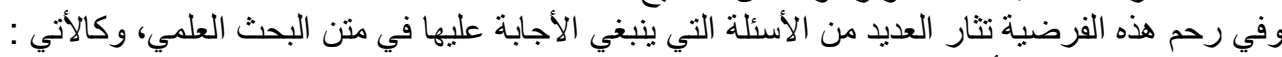

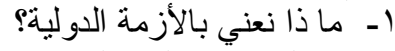

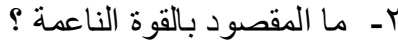

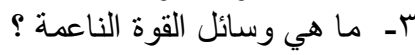

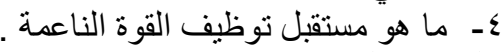

منهجية الدراسة : تعنمد الدراسة على منهجية منكاملة قدر حاجة الباحث لأكثر من منهج في منن الدراسة، وكالاتي : ا ـ المنهج التاريخي : وذلك لحاجة الباحثين في الإشارة الى بعض الوفة الوقائع التاريخية او التجارب السابقة لتوظيف القوة

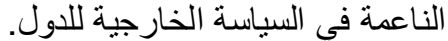

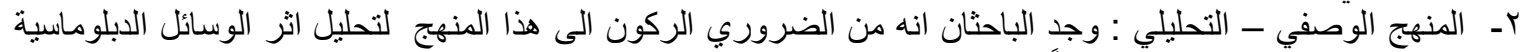
في التقليل من حدة الازمات تمهيداً للعمل على الته التهائها.

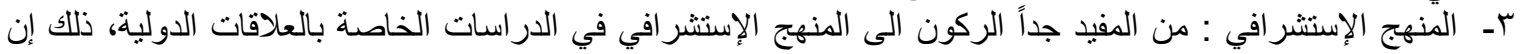

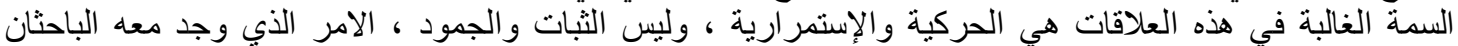

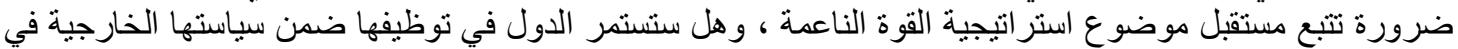

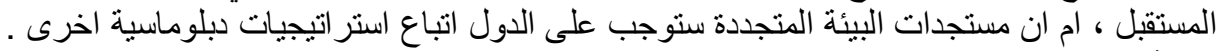

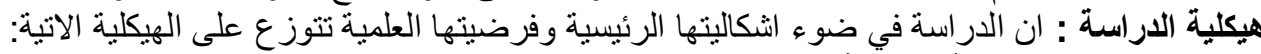

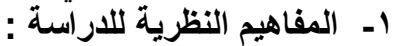

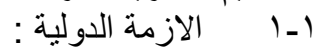
- المفهوم: (-1-1

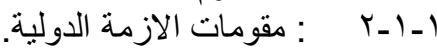

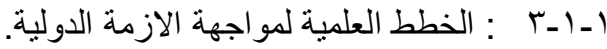

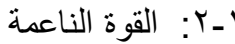


r ب مستقبل توظيف القوة الناعمة في استراتيجية السياسة الخارجية للقوى الدوليه.

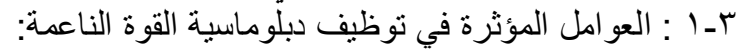

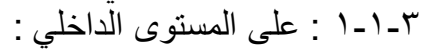

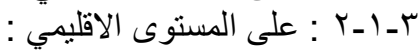

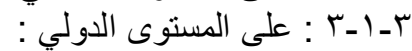

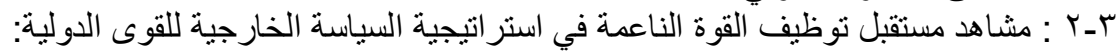

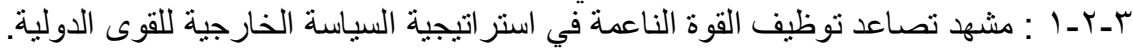

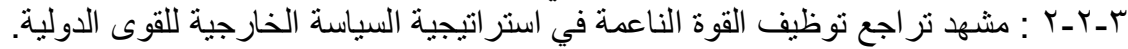

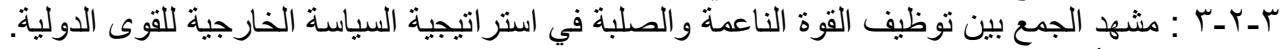

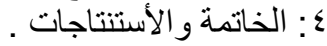

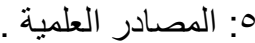

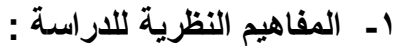

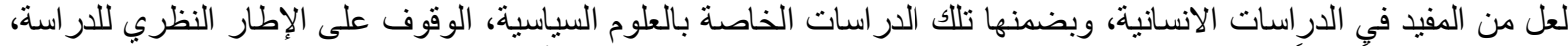

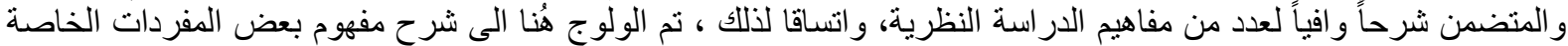

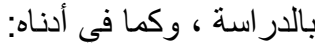

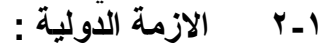

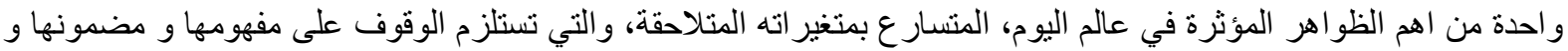

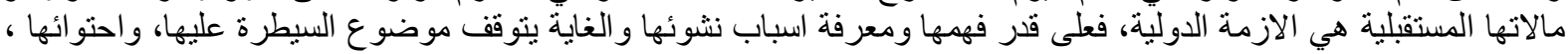

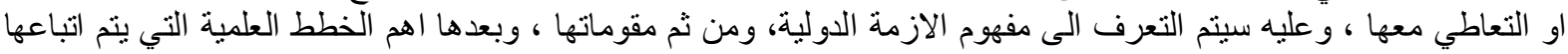

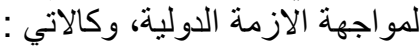

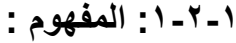

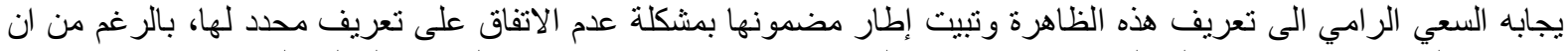

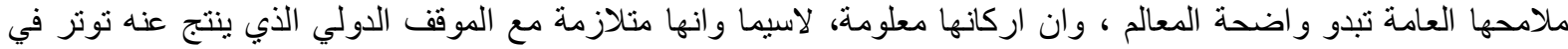

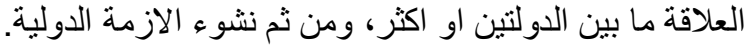

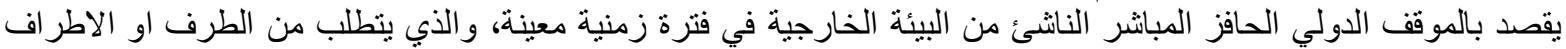

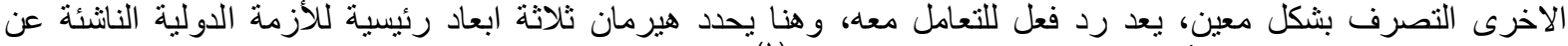

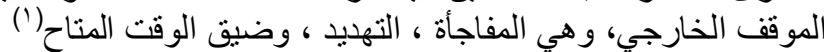

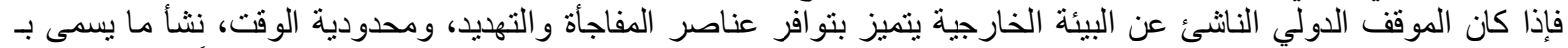

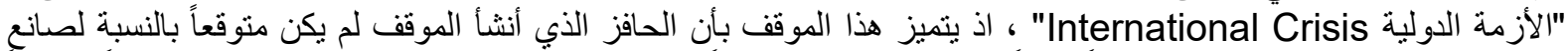

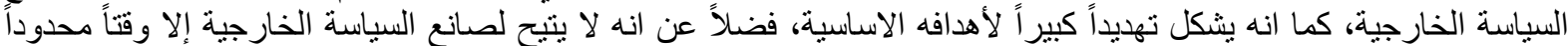

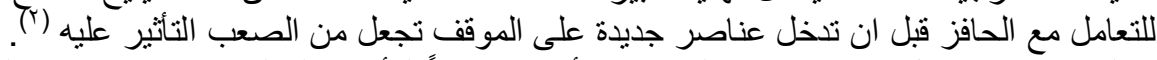

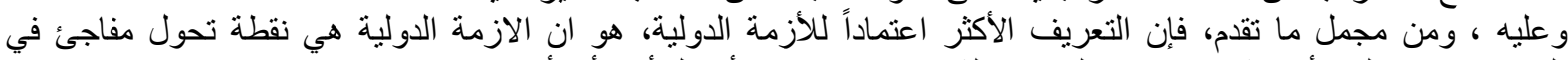

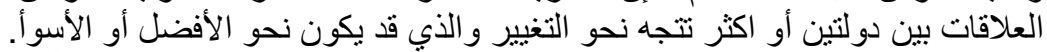

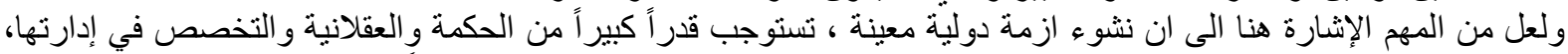

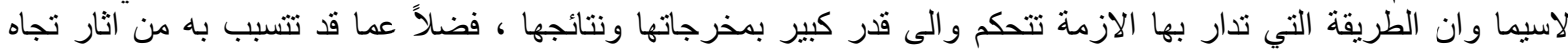

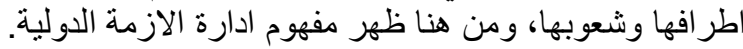

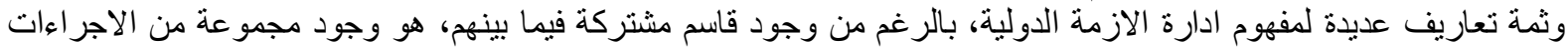

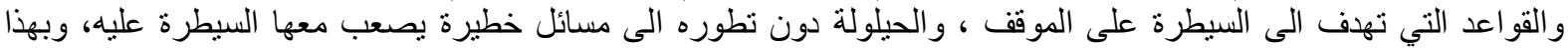

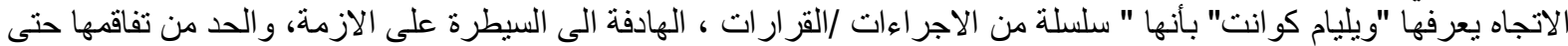

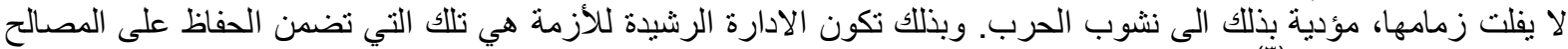

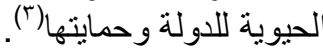

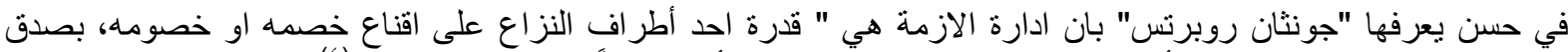

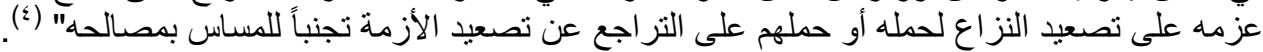

(') ـ محمد و ائل القبسي، استر اتيجية القوة الذكية في إدارة الأزمة الدولية "أزمة واشنطن-طهر ان خلال العام 9 أــ ب أنموذجاً" مجلة دراسات إقليمية، مركز

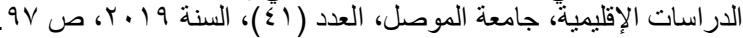

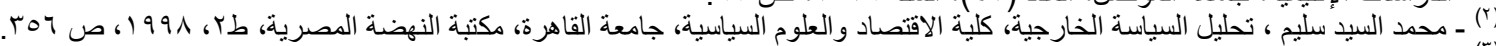

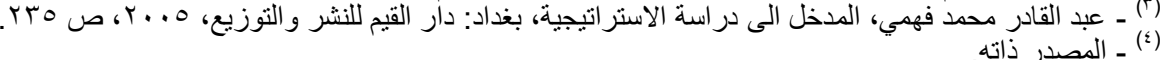




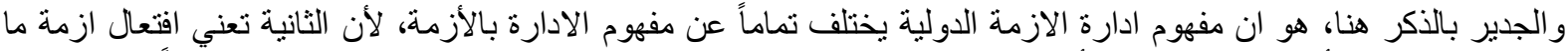

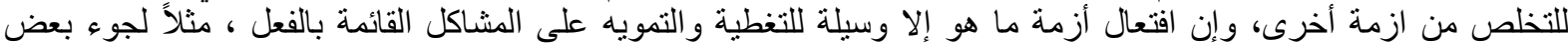

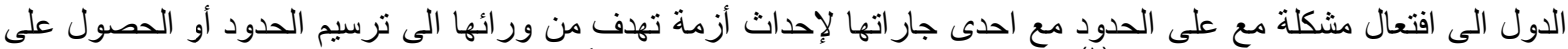

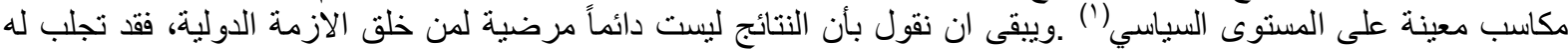

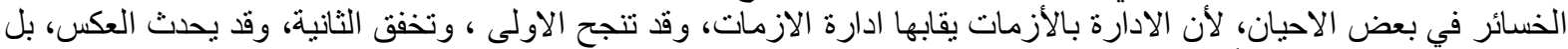

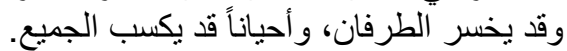

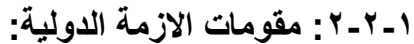

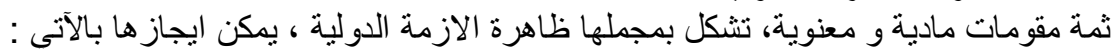

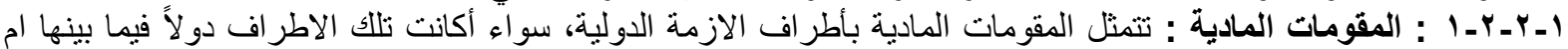

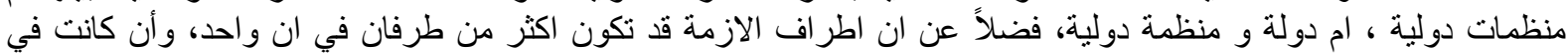

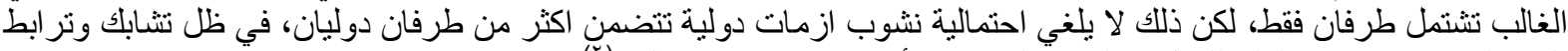

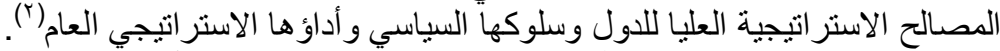

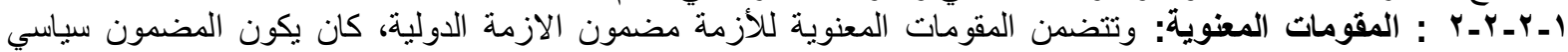

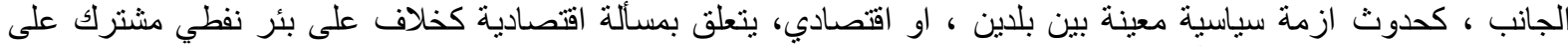

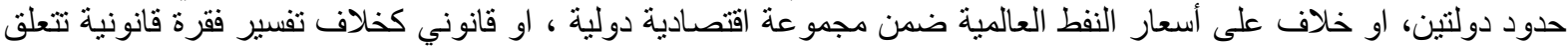

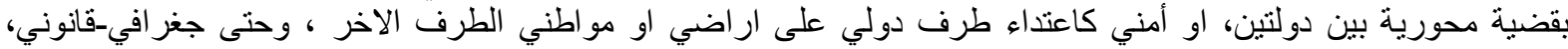

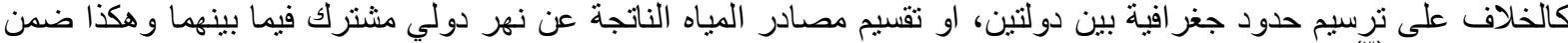

هذه الاتجاهات (")

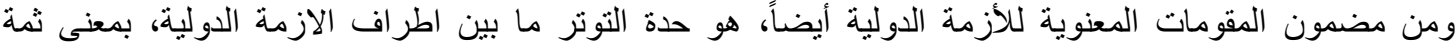

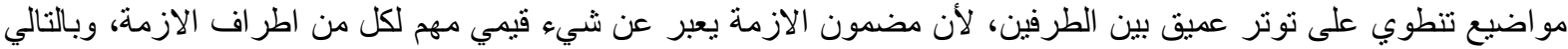

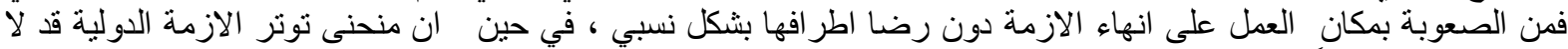

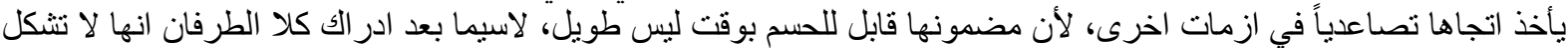

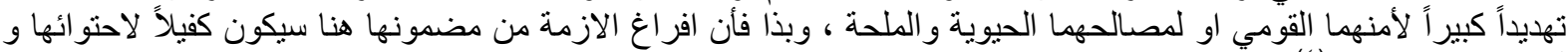

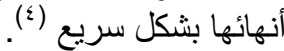

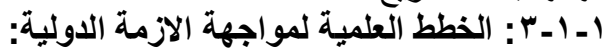

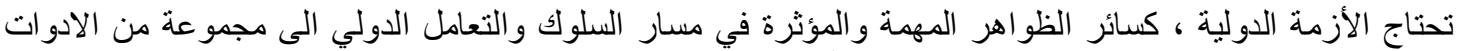

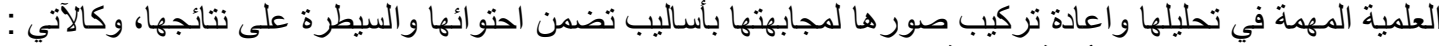

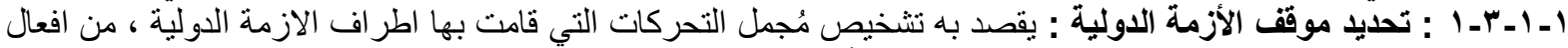

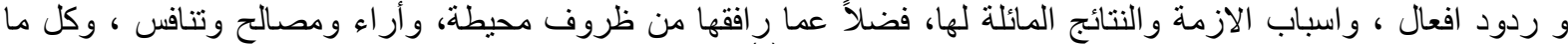

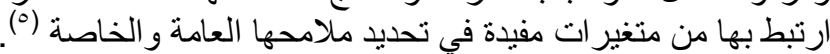

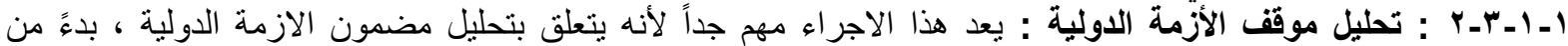

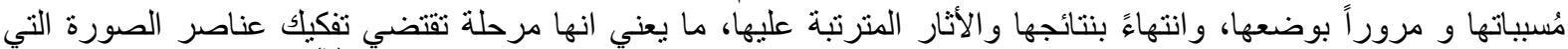

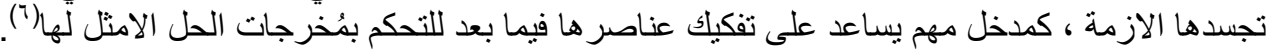

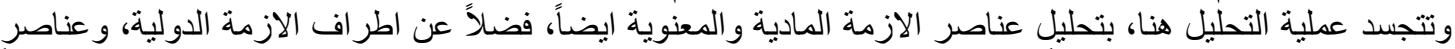

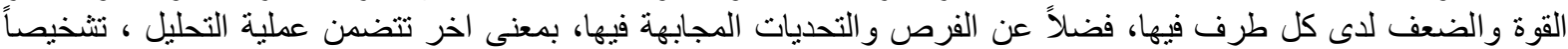

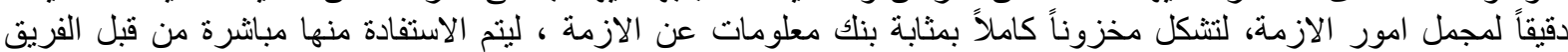

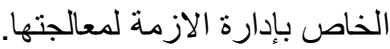

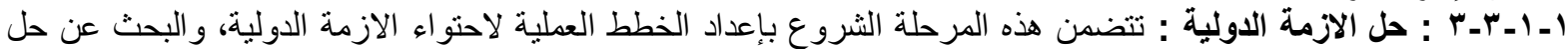

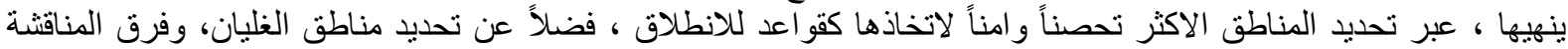

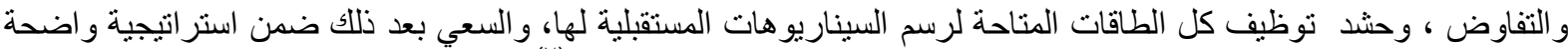

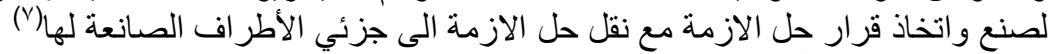

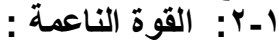

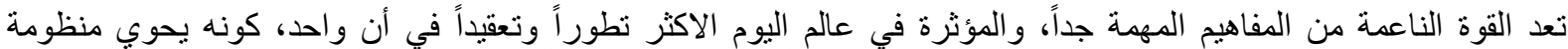

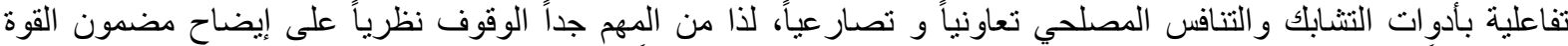

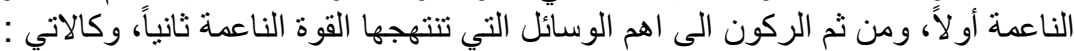

(2)_Chester Alexis C. Buama, Crisis Communication and Crisis Management, Society Publishing,2018, p:32.

(3) -lbid.

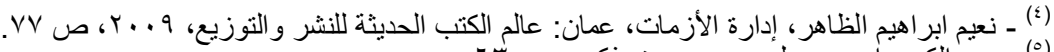

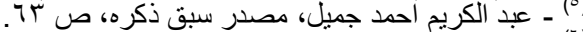

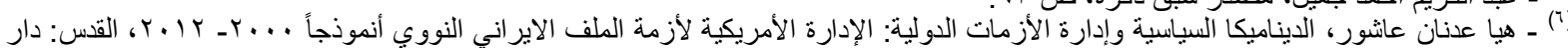

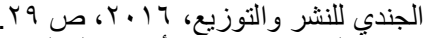

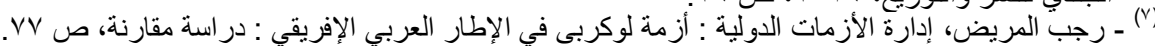




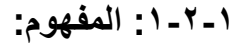

ابتداءً، لعل من المهم الاشارة الى أن القوة الناعمة مصطلح قديم، لكنه لم يتم توظيفه بشكل واضح و و مؤثر الا بعد اعادة صياغته

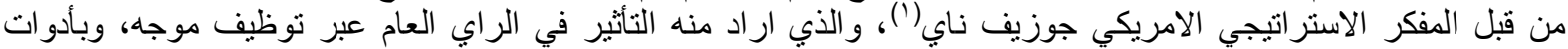

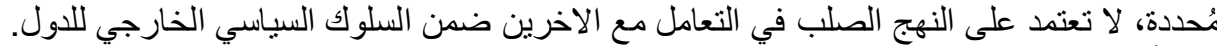

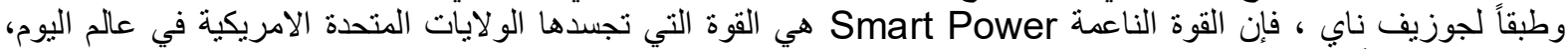

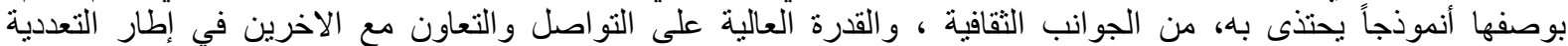

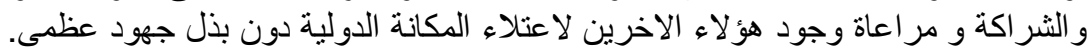

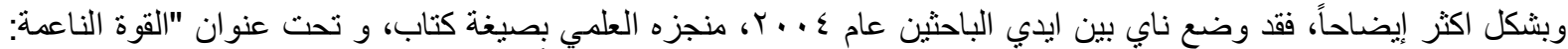

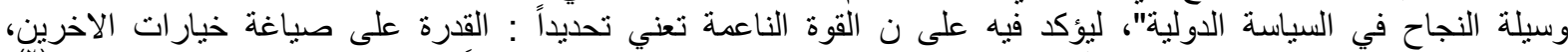

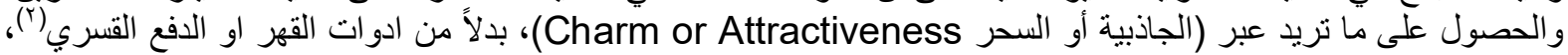

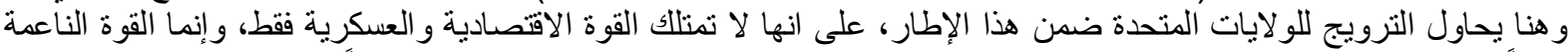

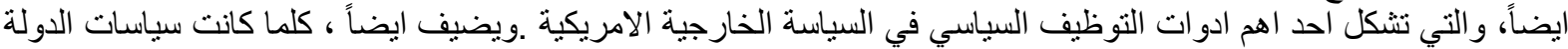

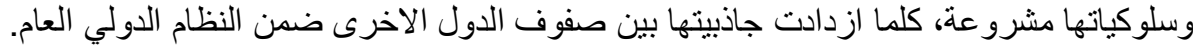

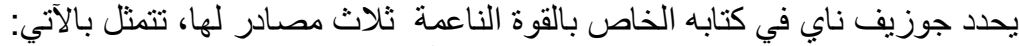

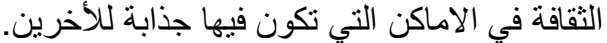

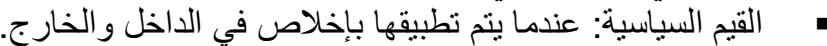

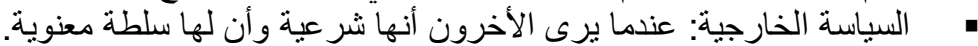

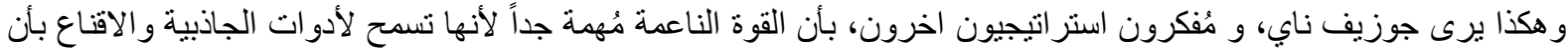

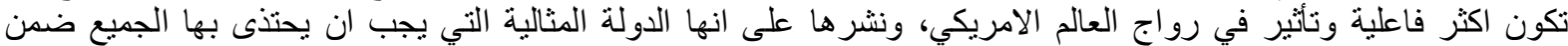
المنظومة العالمية.

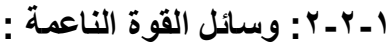
ابتداءً ، تجدر الإشارة الى الن الآراء التاءة تتباين مضمون الوسائل التي تعتكز عليها القوة الناعمة، وهي تسير في طريق الوصول

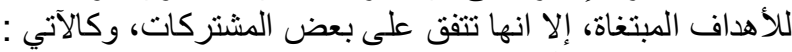

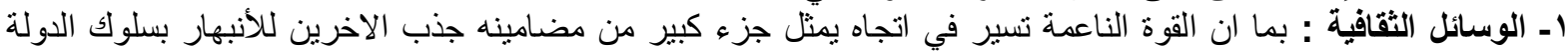

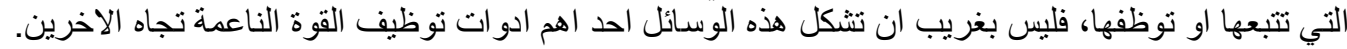

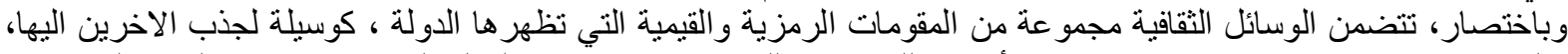
و التي تنم عن توجيه و استهداف مرن يدفع بالأخرين للسير في فلك تحدد مساره ذات الدولة التي التي تتحكم بمدار التقافة التي تبديها

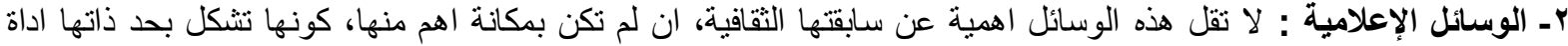

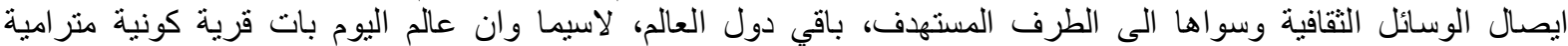

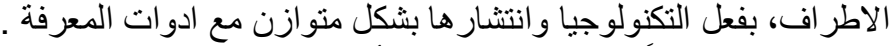

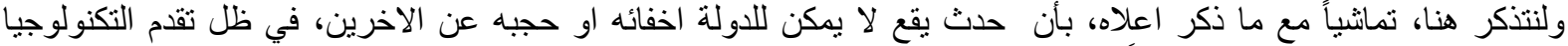

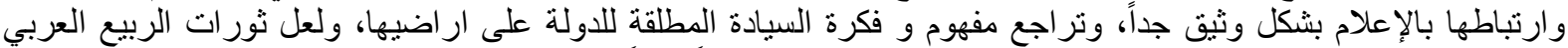

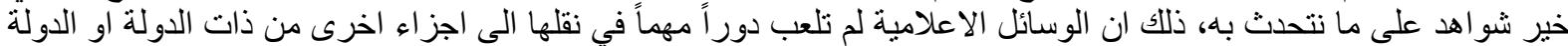

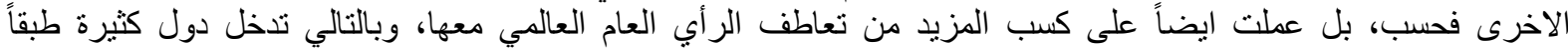

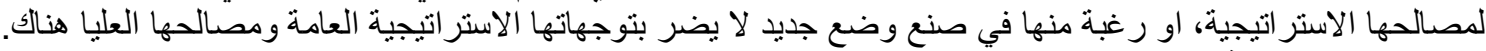

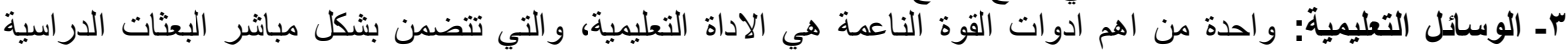

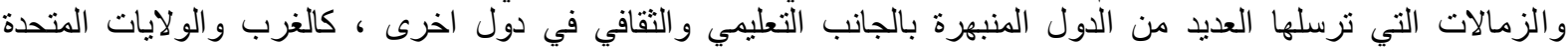

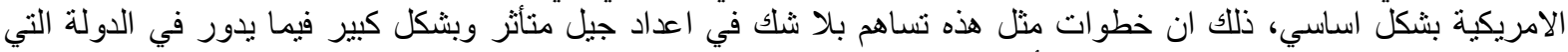

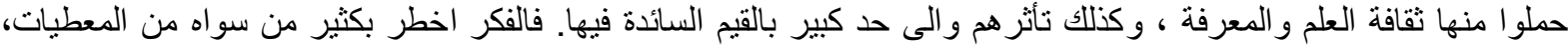
كونه يتجذر في عقول حامليه.

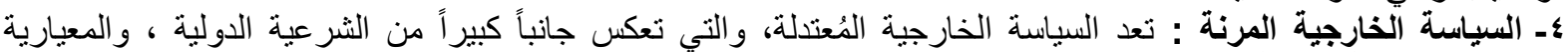

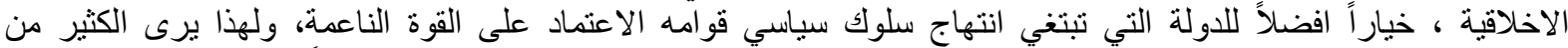

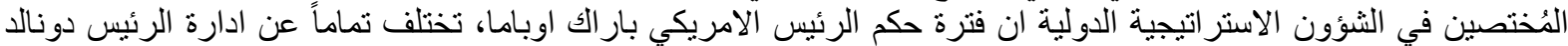

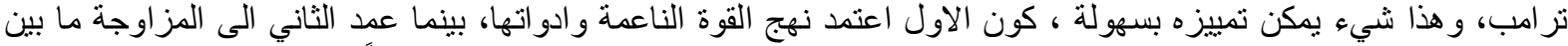

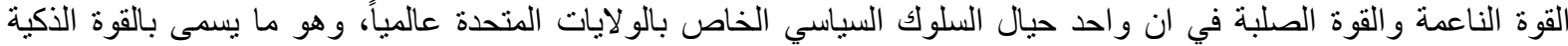

.Smart Power

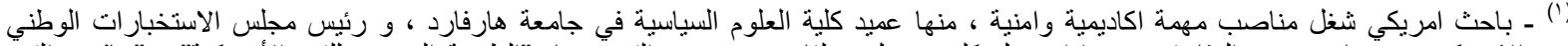

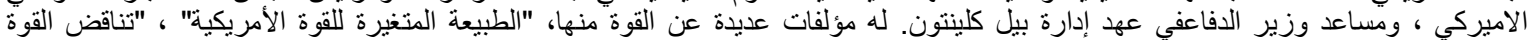

(2) - Joseph S.Nye,The future of power, New york, Public Affairs,2011,p:17. 


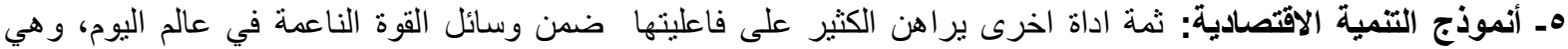

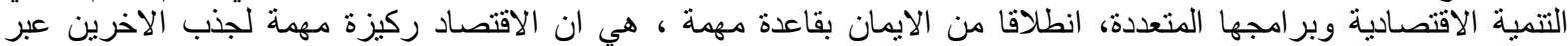

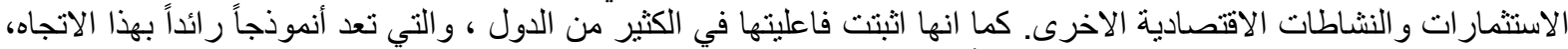

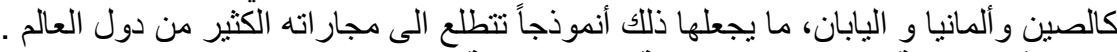

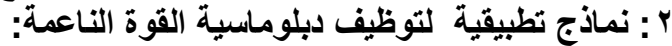

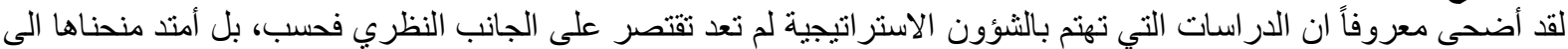

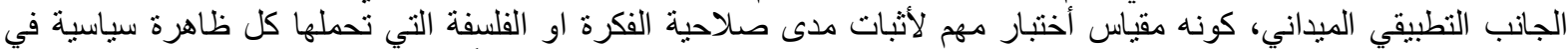

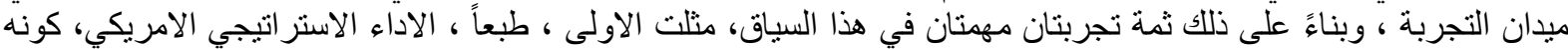

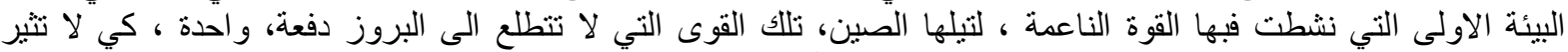

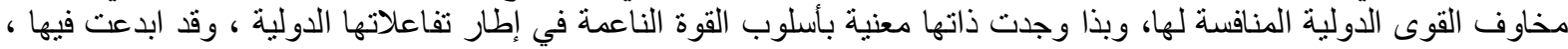

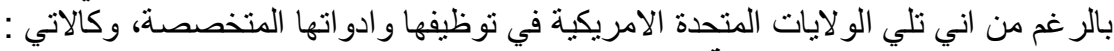

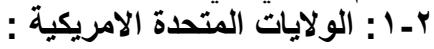

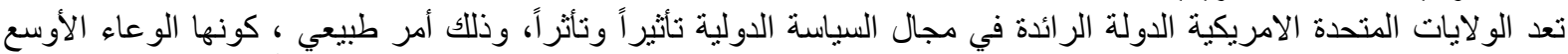

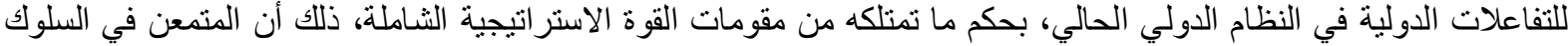

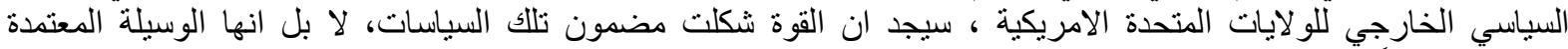

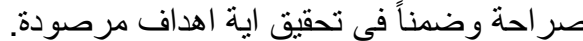

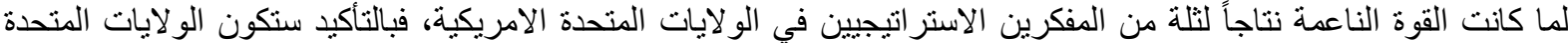

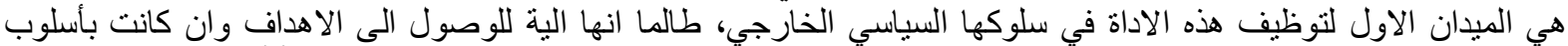

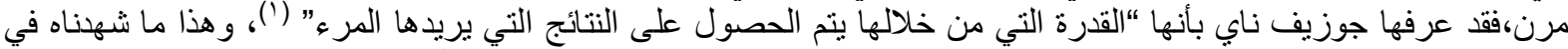

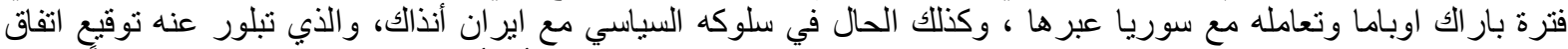

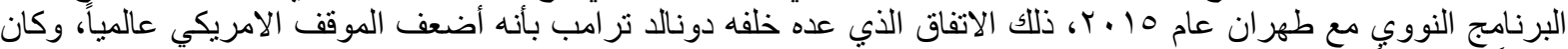

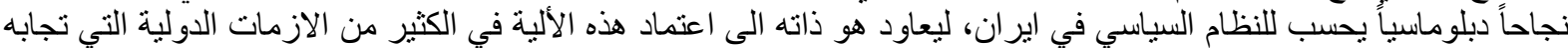

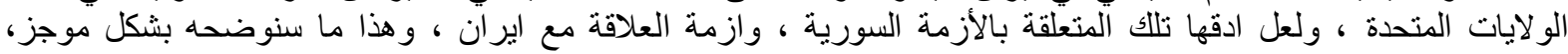
وكالآتي:

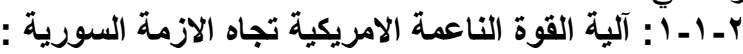

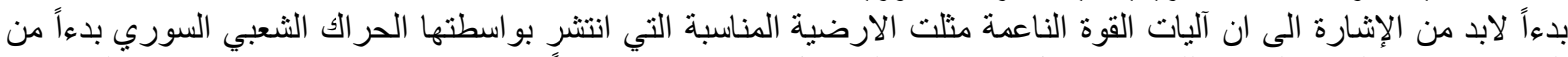

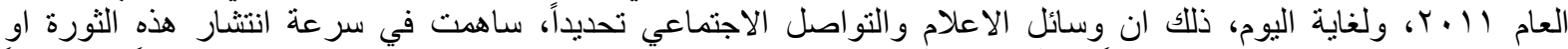

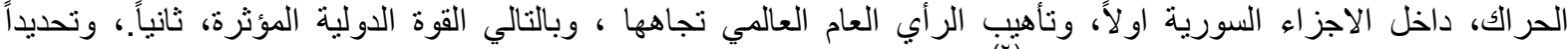

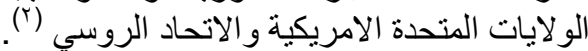

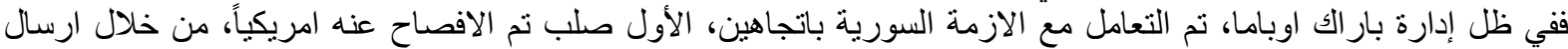

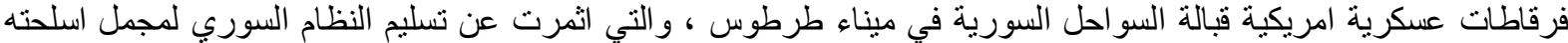

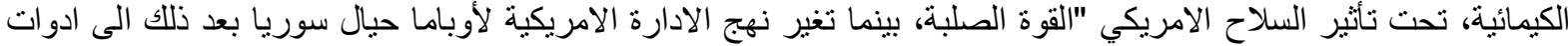

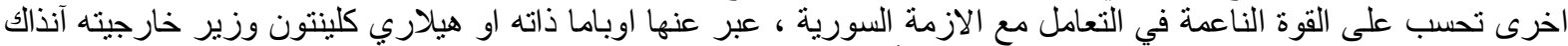

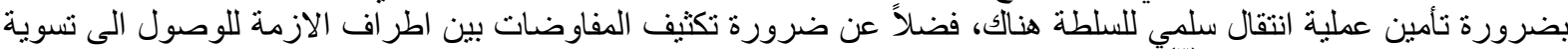

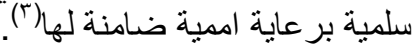
أما موقف الادارة الامريكية التي يمثلها الرئيس الامريكي الحالي دونالد ترامب في التعامل مع الازمة السورية عبر الية القوة

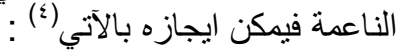

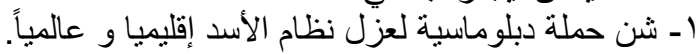

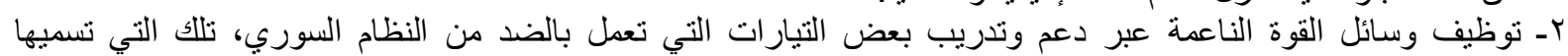

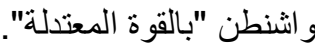

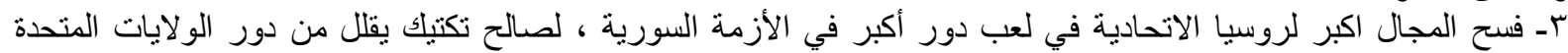

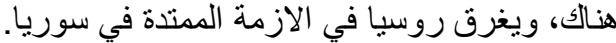

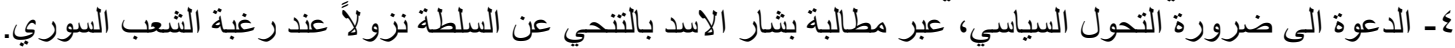
0ـ الاعلان عن استعداد الثركات الأمريكية للمساهمة في اعادة بناء سوريا بعد عملية التغيير السياسي هناكي.

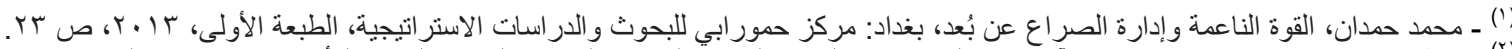

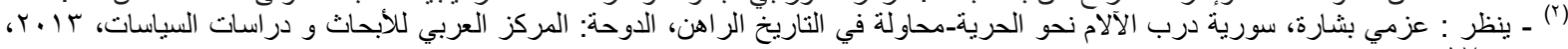

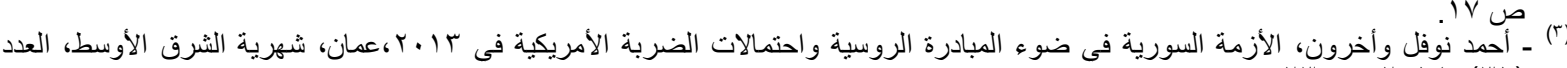
(4) -Lara Seligman, The Unintended Consequences of Trump's Decision to Withdraw From Syria, Foreign Policy, January 28,2019,On website :

https://foreignpolicy.com/2019/01/28/unintended-consequences-trump-decision-withdraw-syria/ 


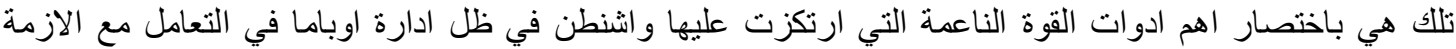

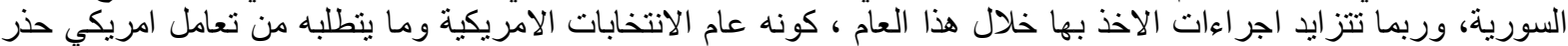

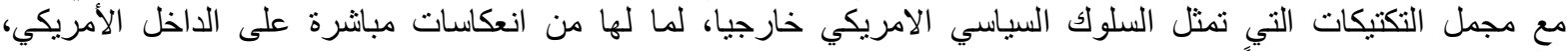
و المو اطن الامريكي تحديداً.

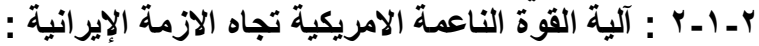

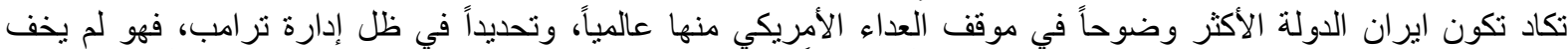

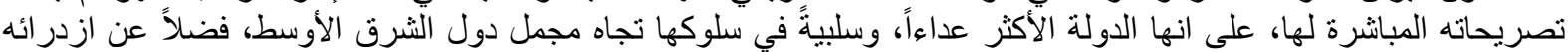

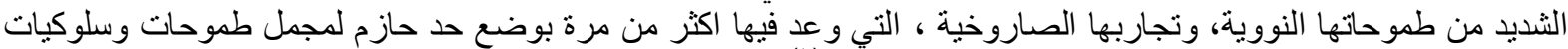

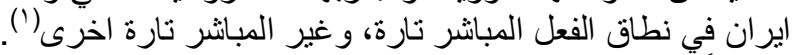

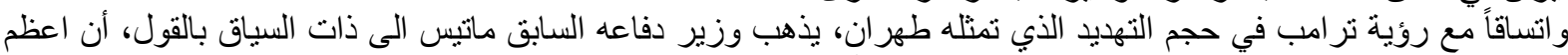

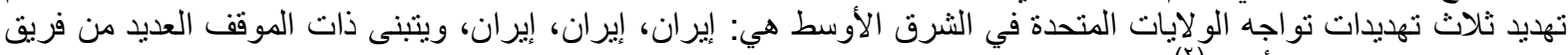

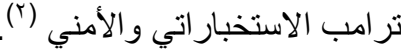

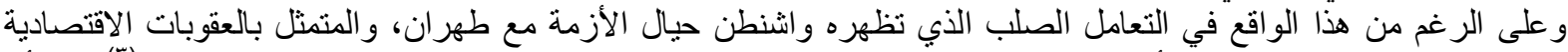

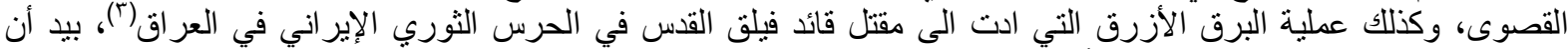

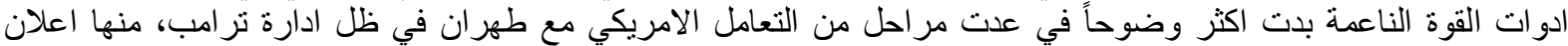

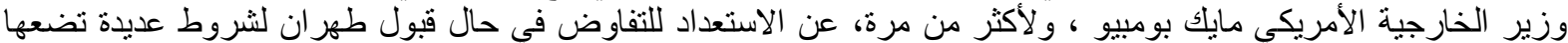

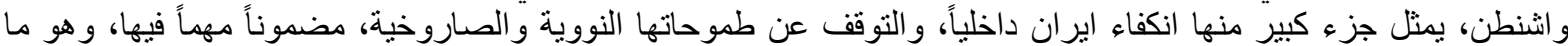

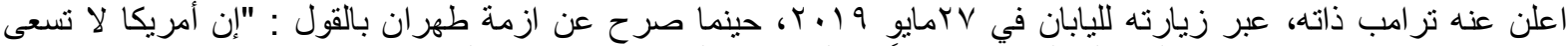

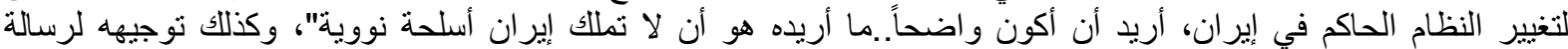

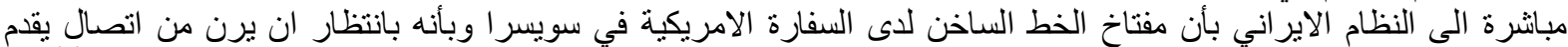

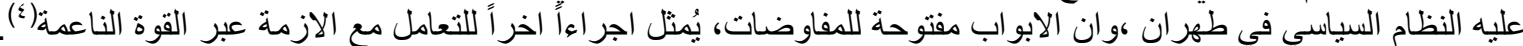

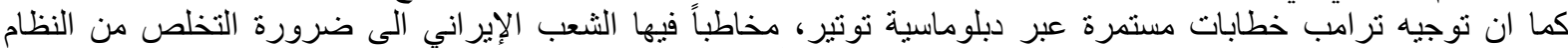

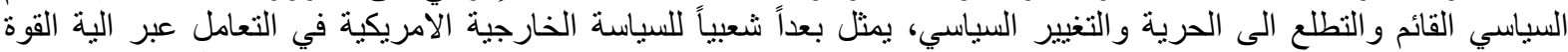

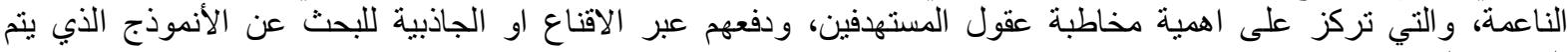
التسويق اليه.

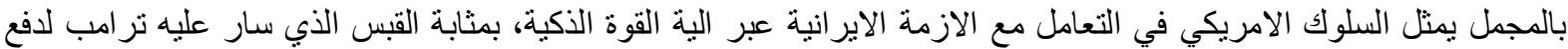

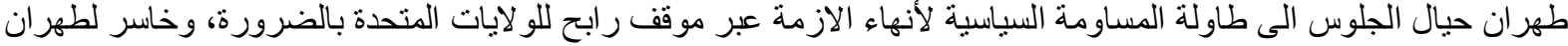

بدرجات مقبولة.

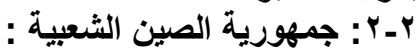
تعد الصين ، الدولة الريائدة في مجال نوظيف الئيف الية القوة الناعمة عالمياً، بعد الولايات المتحدة الامريكية، ولعل هذا الامر يعود

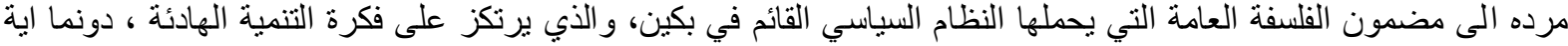
اثارة لمشاعر التوجس و المنافسة التي تبديها القوى الدولية الاخرى تجاهها، وتثق الو لايات المتحدة الامريكية في مقدمة هذه

القوى(0)

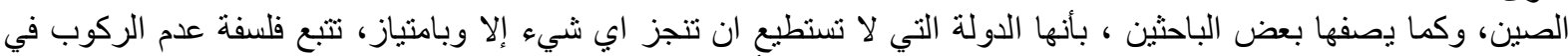

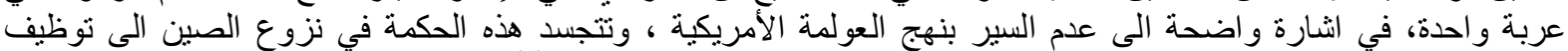

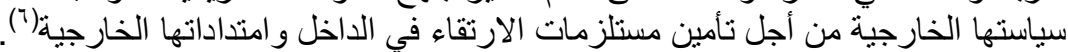

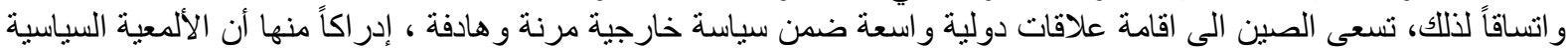

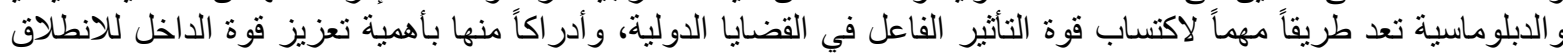

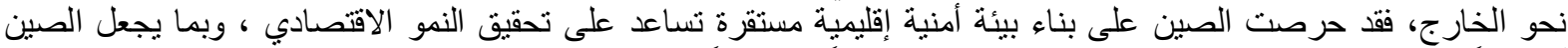

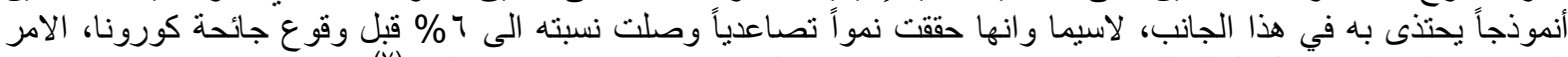

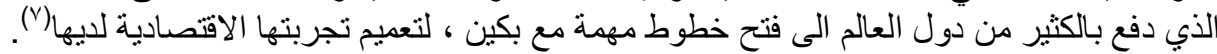

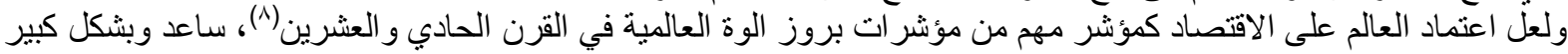

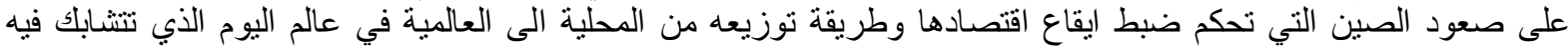

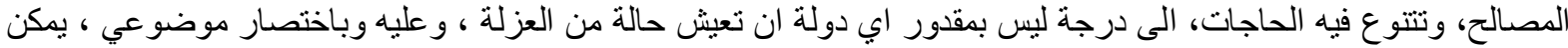

(') (ب) - محمد وائل القيسي، إستراتيجية القوة الذكية في إدارة الأزمة الدولية، مصدر سبق ذكره، ص 119.

(3) - Jonathan Stevenson, American Foreign Policy Is Broken. Suleimani's Killing Proves It, New york Times, Jan.4,2020,On website : https://www.nytimes.com/2020/01/04/opinion/trump-soleimani-strike.html

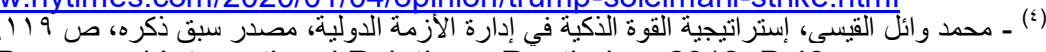

(5) - Hongyi Lai، Yiyi Lu,China's Soft Power and International Relations, Routledge, 2012. P:43.

${ }^{(6)}$ Emilian Kavalski, Asian Thought on China's Changing International Relations, Springer, 2014 .p:56.

(7) - Lukas K. Danner, China's Grand Strategy: Contradictory Foreign Policy?,USA:Florida International University,2018,p:27.

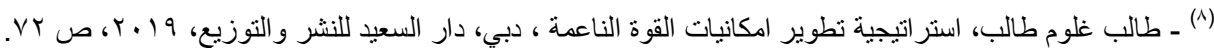


ايجاز الاليات التي تعتمدها الصين وهي تسير وفق اسلوب القوة الناعمة في مجابهة الازمات الداخلية و الاقليمية والدولية، وكالاتي:

1- النهوض السلمي : ابلغ فلسفة تتضنمنها السياسة الخارجية الصينية في النهوض و التتقل الى الامام صوب مركز الثقل العالمي

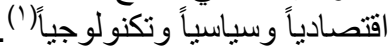

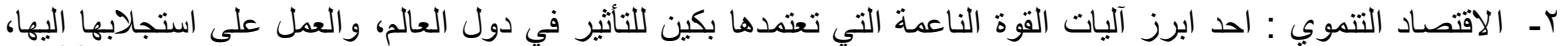

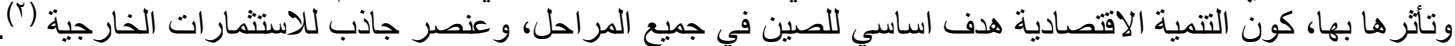

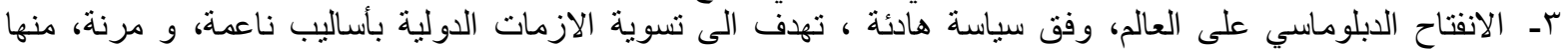

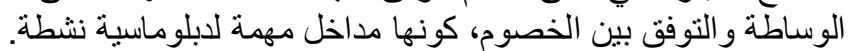
عـ اليوان الصيني كعملة قيادية مؤثرة في الاقتصنياد العالمي ، و والسعي الصيني المستمر لتعزيز مركزه المالي قياساً باليورو

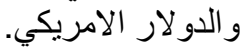

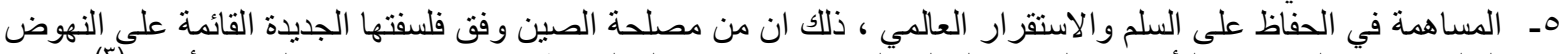

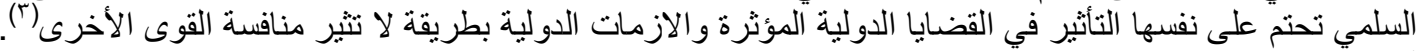

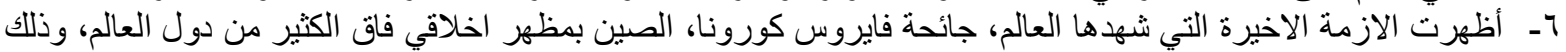

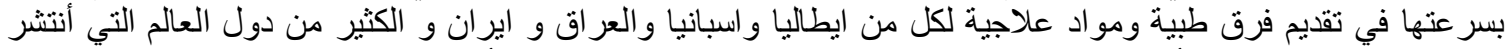

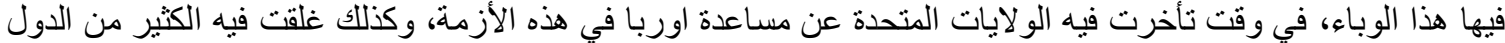

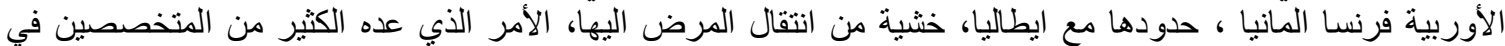

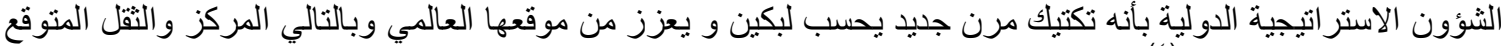

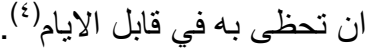

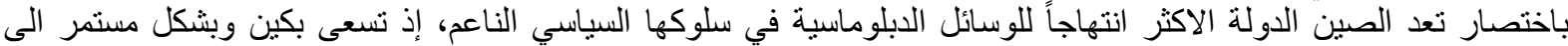

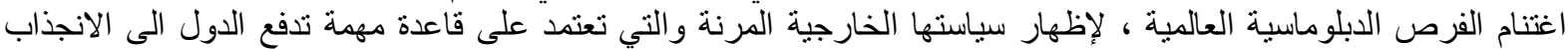

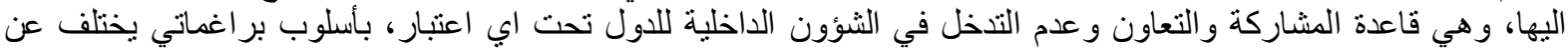

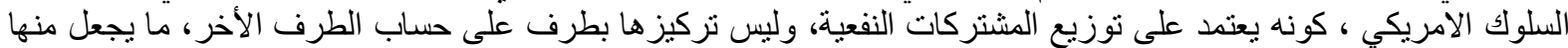

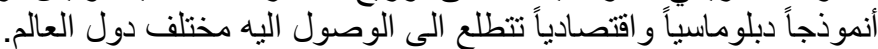

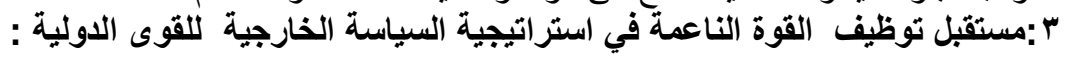

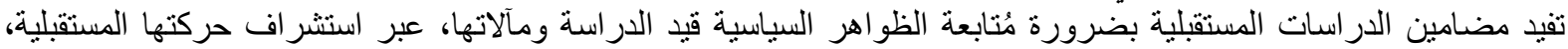

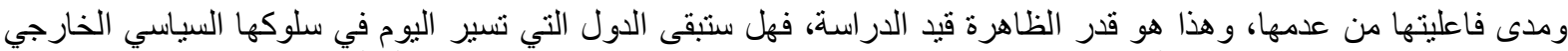

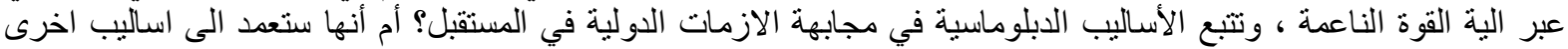

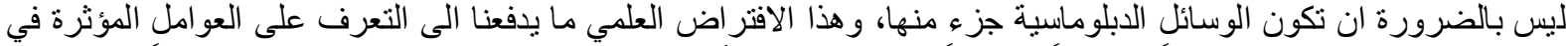

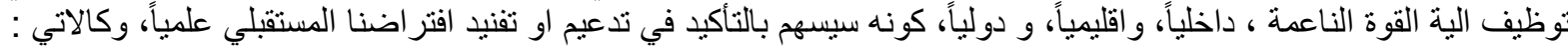

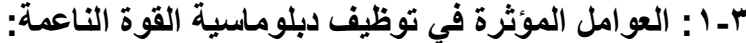

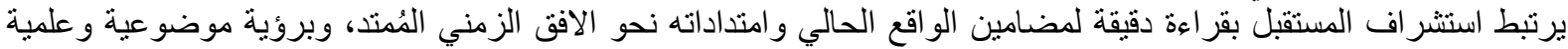

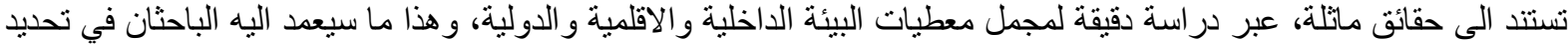

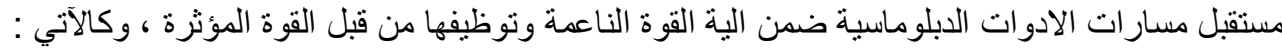

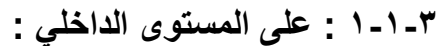
يسود أتفاق شبه عام بين مُجمل الباحثين و المختصين بالعلاقات الدولية والثؤون التون الاستر اتيجية على ان الاقتصاد و التكنولوجيا

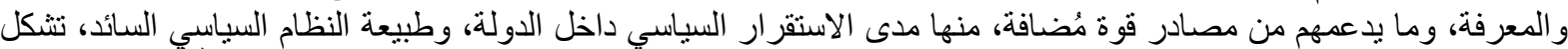

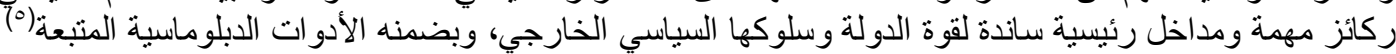

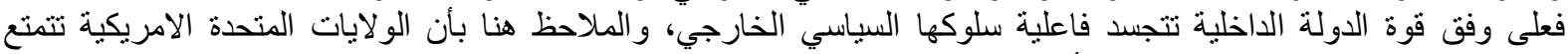

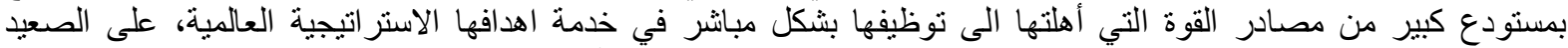

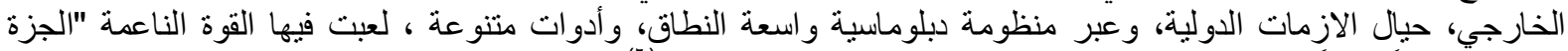

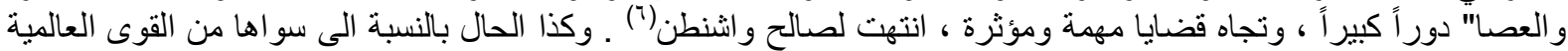
المؤثرة.

(1) -lbid. 27.

(؟) ـ جانغ يون لينغ- ، ترجمة: د.آيه محمد كمال، الحزام والطريق : تحولات الدبلوماسية الصينية في القرن ال آى، دار صفصاف للنشر والتوزيع، (T)

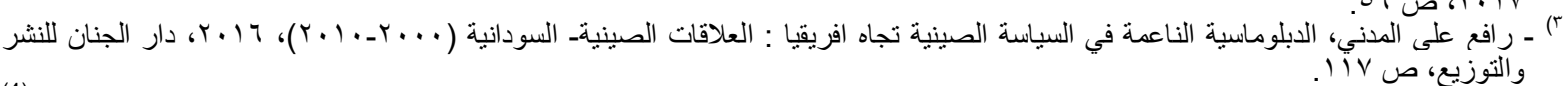

(4) -China sends doctors and masks overseas as domestic coronavirus infections drop, Mars, The Guradian, 19,2020, on the website :

https://www.theguardian.com/world/2020/mar/19/china-positions-itself-as-a-leader-in-tackling-thecoronavirus

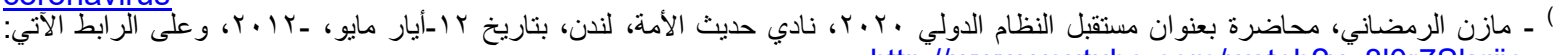
http://www.youtube.com/watch?v=810r7Skqiio

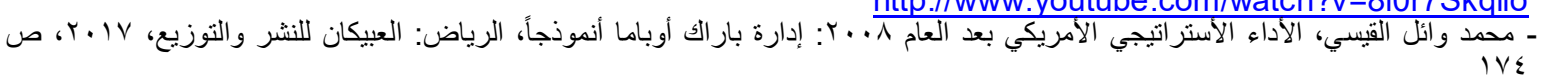




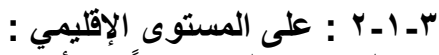

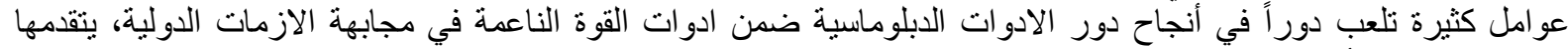
عاملين مؤثرين، أولهما مدى ضبط ايقاع الئل السلوك السياسي الخارجي الهادف للقوى الدولية المؤثرة حيال بيئتها الإقليمية، فعليه

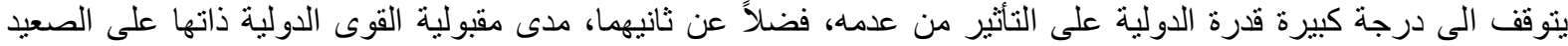

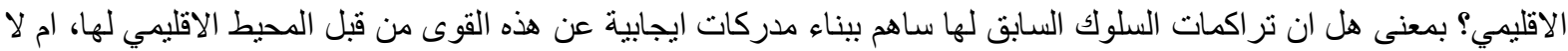

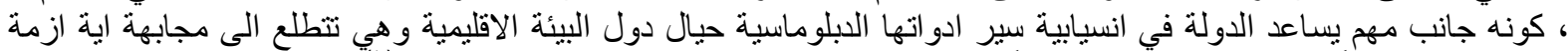

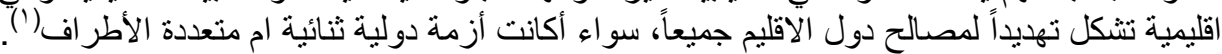

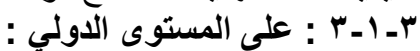

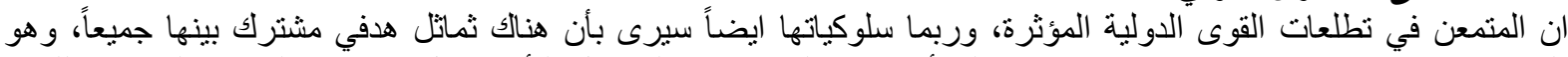

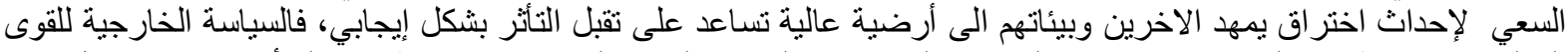

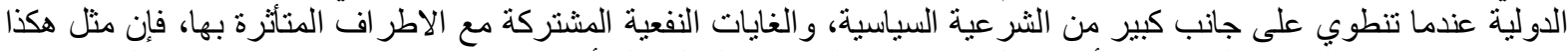

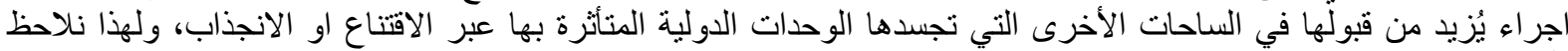

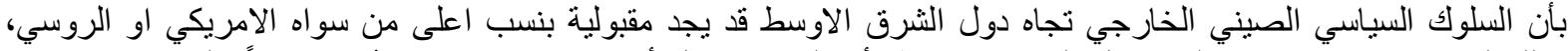

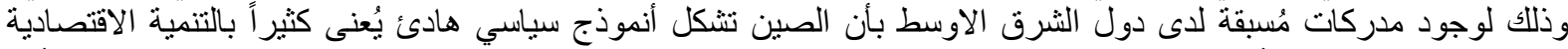

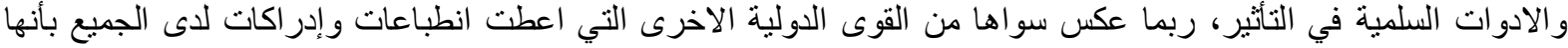

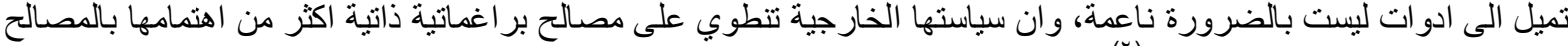

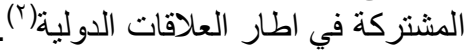

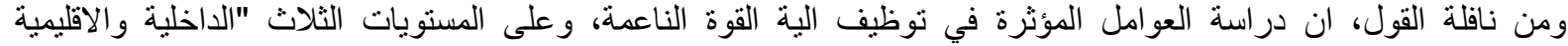

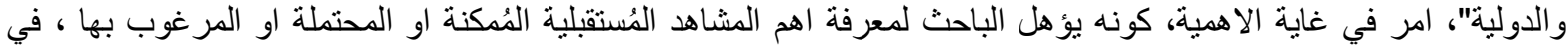

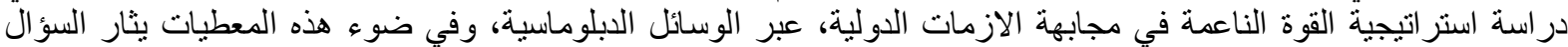

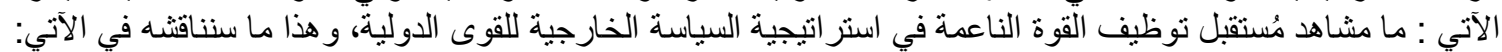

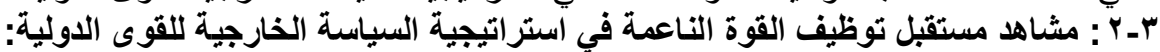

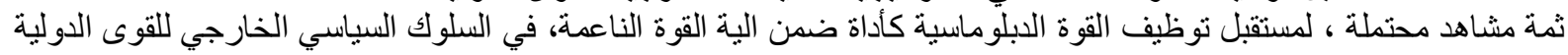

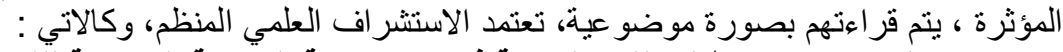

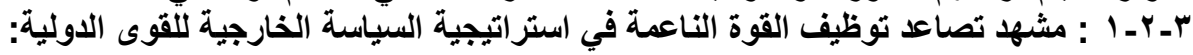

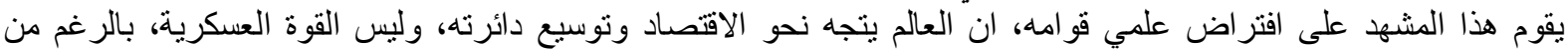

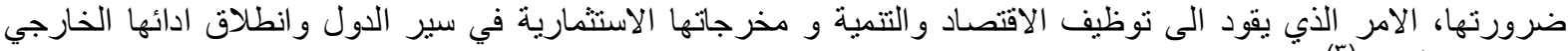

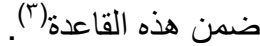

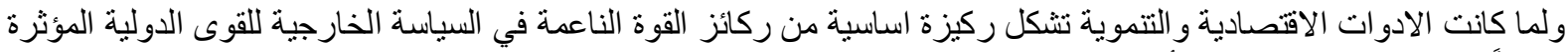

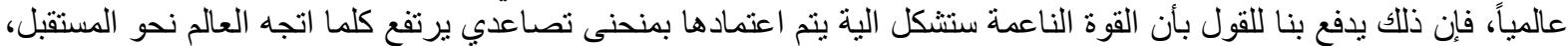

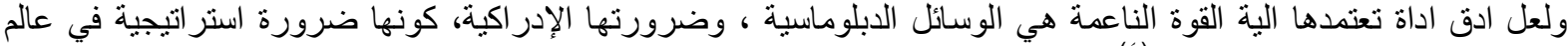

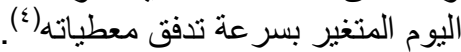

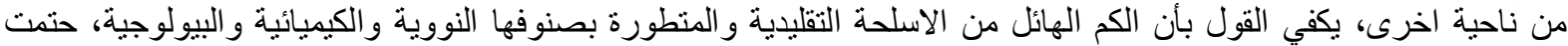

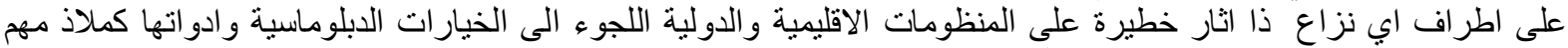

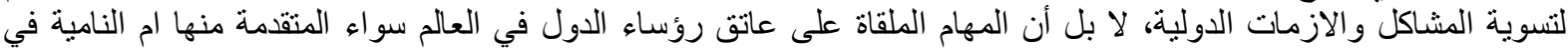

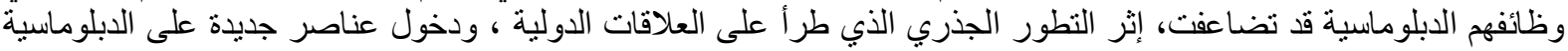

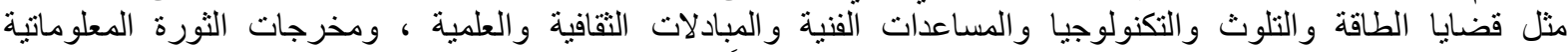

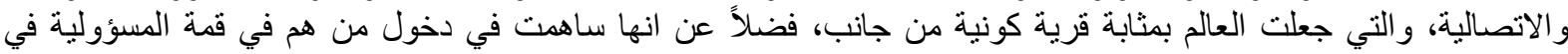

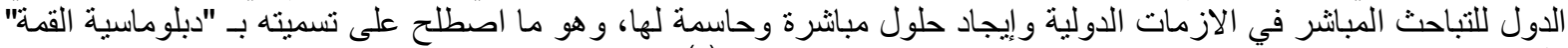

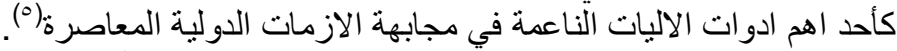

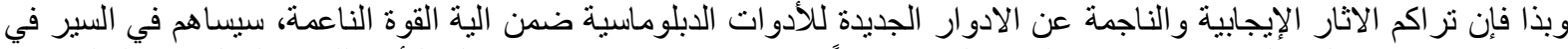

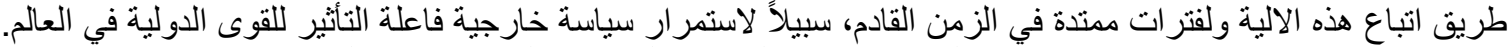

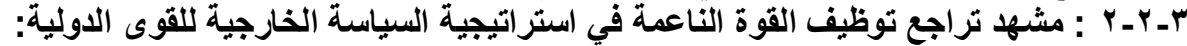

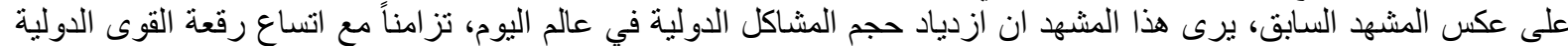

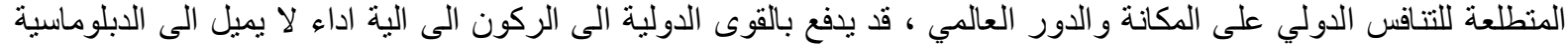

(1) - Anders Corr, Great Powers, Grand Strategies: The New Game in the South China Sea, Naval Institute Press,2018,p:82.

(2) - Marc Lanteigne, Chinese Foreign Policy: An Introduction, London: Routledge,2013,p:167.

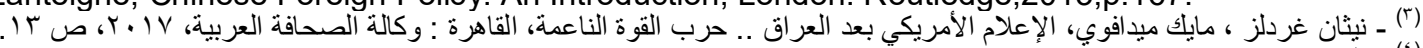

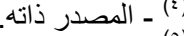

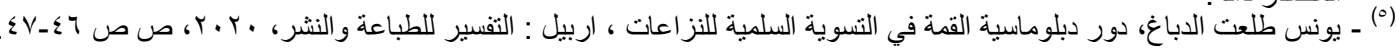


و السلوكيات المرنة في سياساتها الخارجية ، بقدر ميلانها الى ادوات السلوك الصلب في السياسة الخارجية، كالعقوبات الاقتصادية

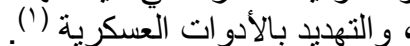

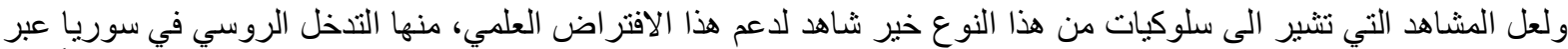

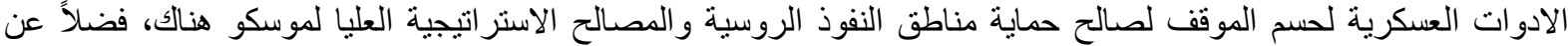

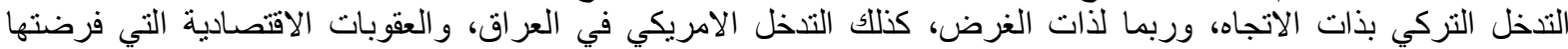

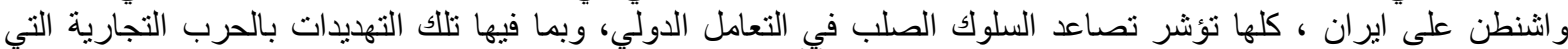

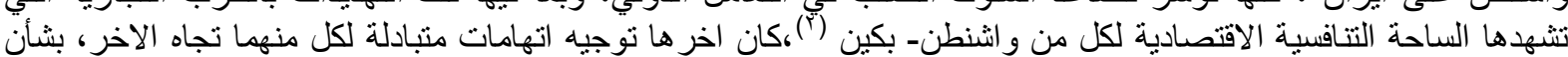

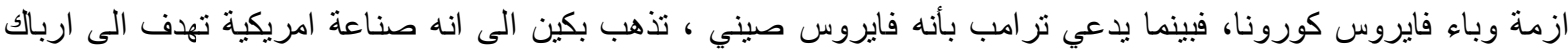
الاقتصاد الصيني.

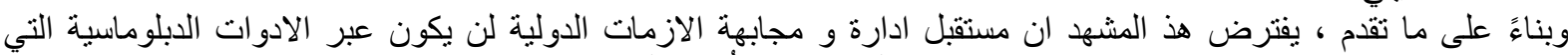

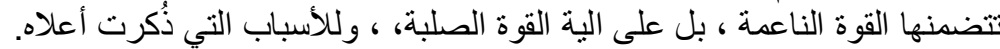

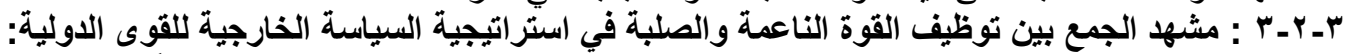

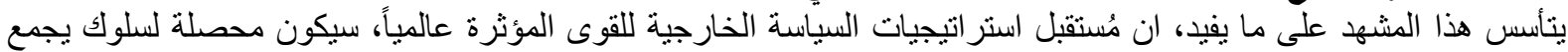
بين ادوات القوة الناعمة والصلبة في ان واحد ، و هو ما اصطلح على تسميته بالقوة الذكية Smart Power، في الادبيات

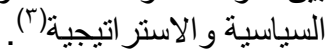
وتبعاً لذلك، يقترن هذا المشهد بحالة افتراضية تقع في الوسط بين مشهدي تصاعد توظيف القوة الناعمة في استر اتيجية السياسة

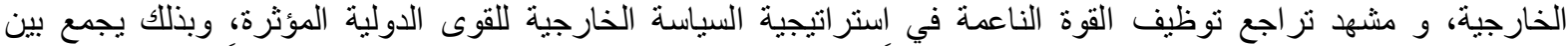

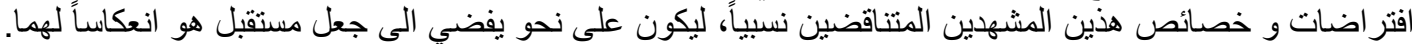

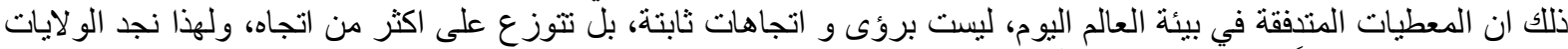

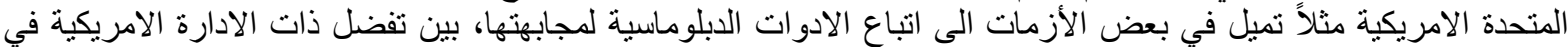

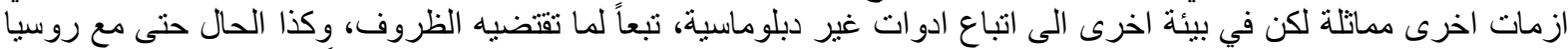

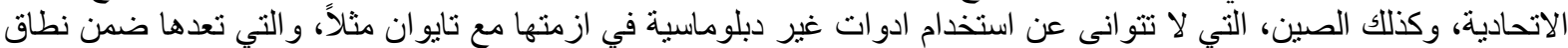

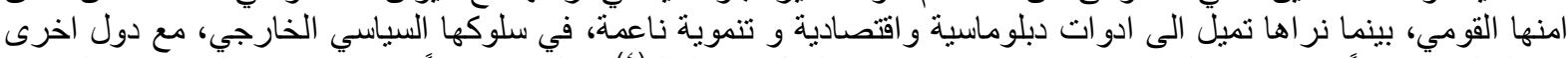

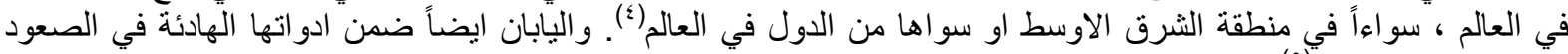
على نطاق شرق اسياً(م).

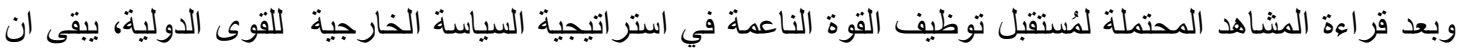

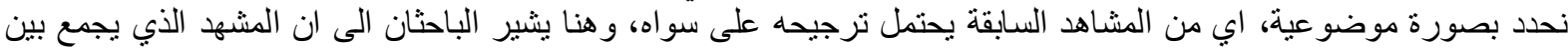

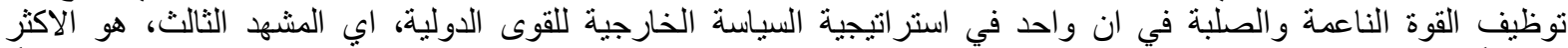

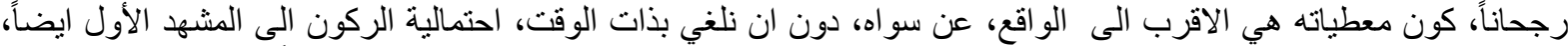

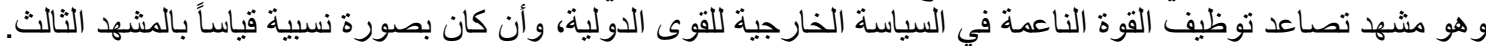

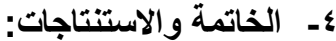

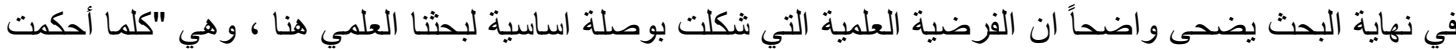

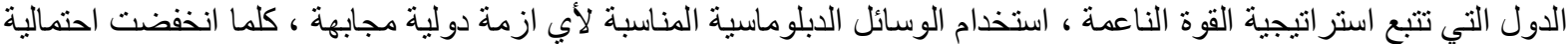

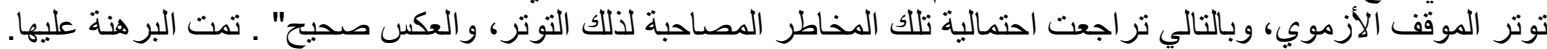

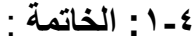

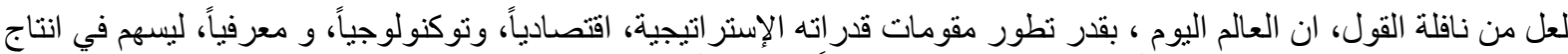

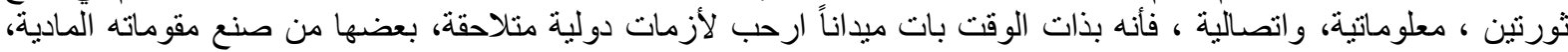

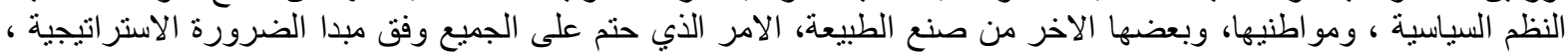

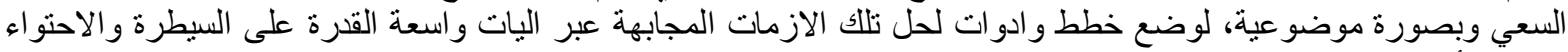

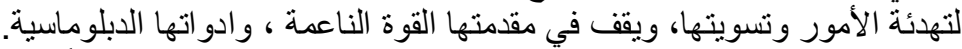

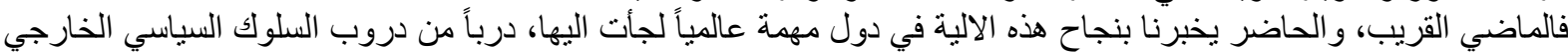

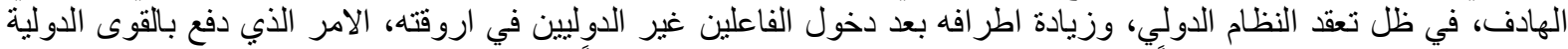

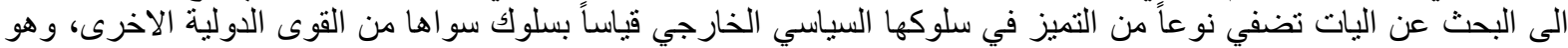

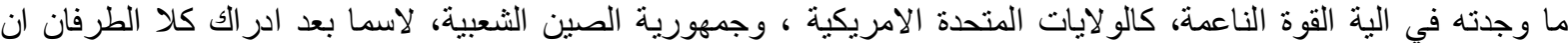

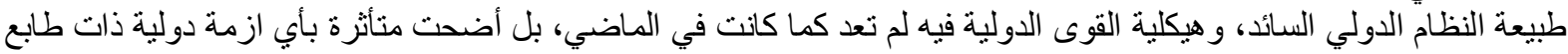

(1) - Fareed Zakaria, The post American world, New york, 2008,p:82.

(2) -See: Carol Atkinson, Military Soft Power: Public Diplomacy through Military Educational Exchanges,UK, Rowman littlefield,2014.

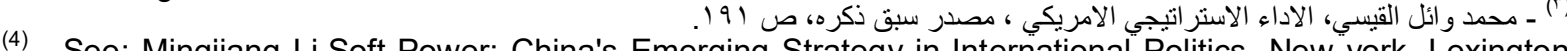
-See: Mingjiang Li,Soft Power: China's Emerging Strategy in International Politics, New york, Lexington Books.2009.

(0.- حسيب الدبدوي، اليابان ودبلوماسية القوة الناعمة : استراتيجية المحيطين الهندي-الهادئ، منطقة حرة ومفتوحة، الرياض: مركز الملك فيصل للبحوث 


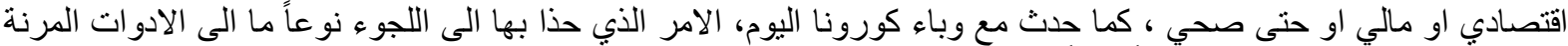

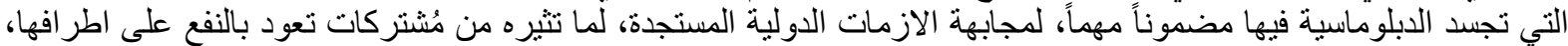

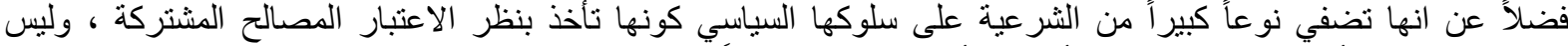

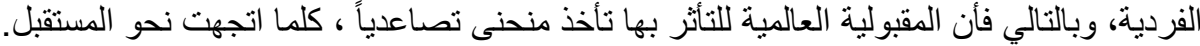

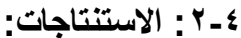

وتبعاً لما تقام، فأن هناك استتناجات تم التوصل الئها، لتشكل ثمرة جها الباحثان عليماً، وكالأتي :

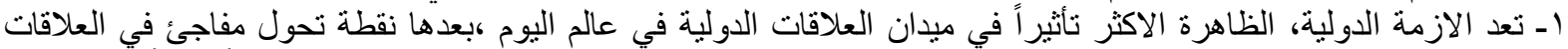

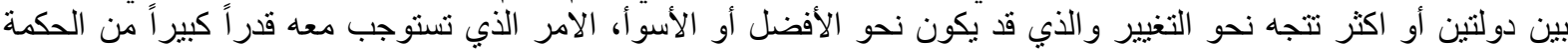

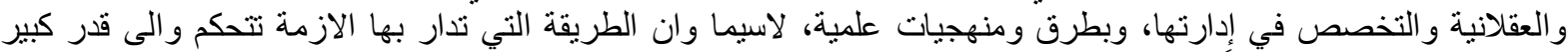

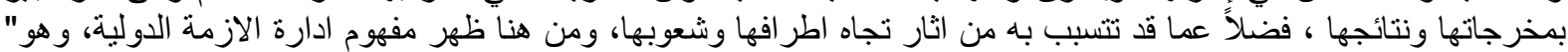

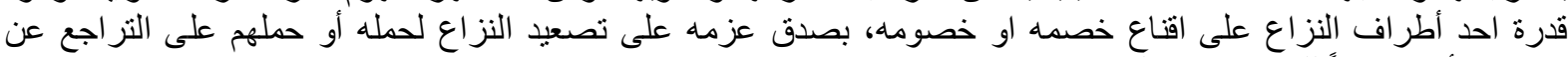

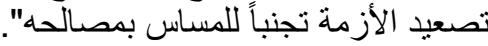

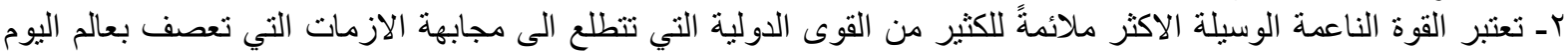

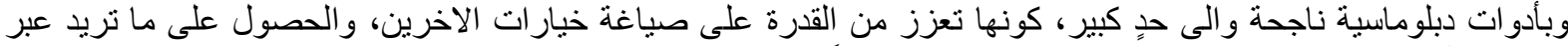

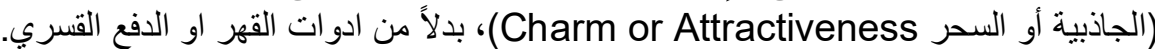

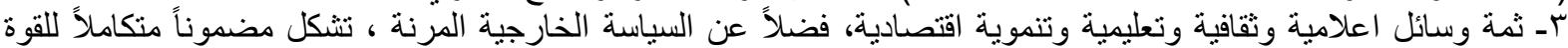
الناعمة ، كآلّة من اليات التوظيف اعلية في السياسة الخارجية للقوى الدولية المؤثرة في عالم اليوم الاكثر نرابطاً و تثنابكاً مصلحياً

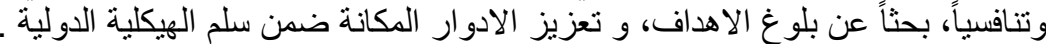

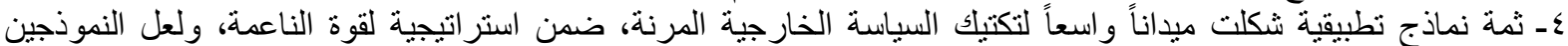

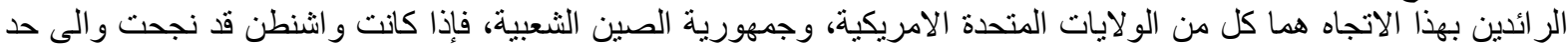

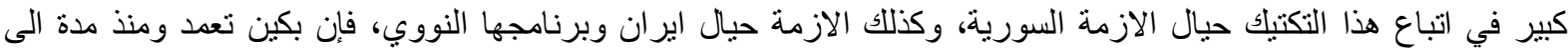

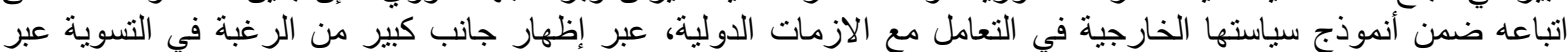

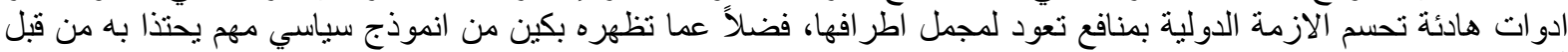

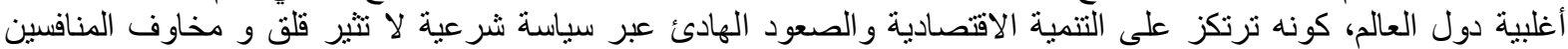
الدوليين حيالها.

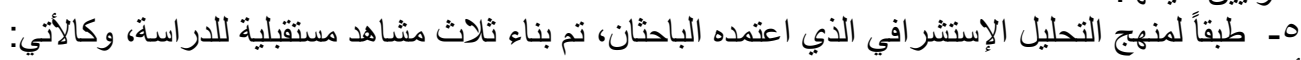

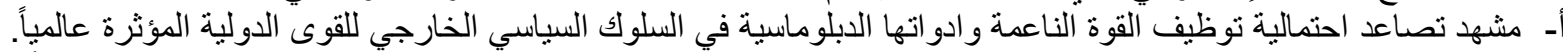

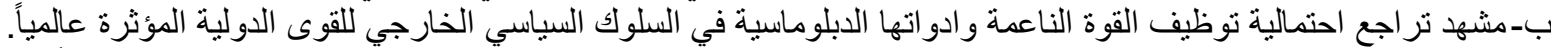

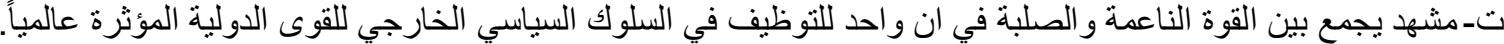

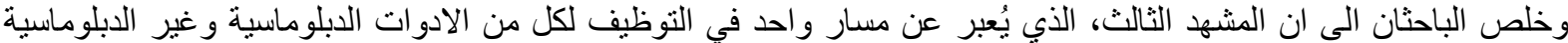

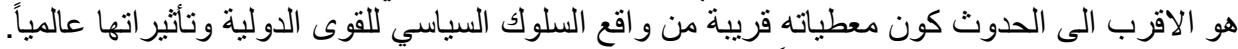

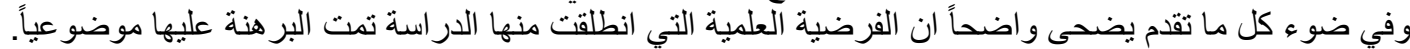

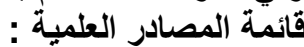

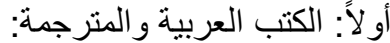

ا - محمد السيد سليم ، تحليل السياسة الخارجية، كلية الاقتصاد والعلوم السياسية، جامعة القاهرة، مكتبة النهضة المصرية، ط؟،

.1991

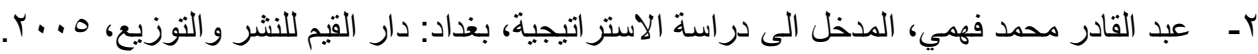

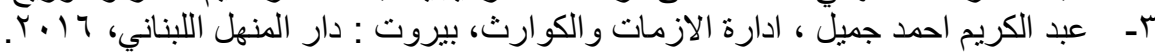

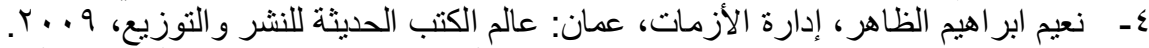

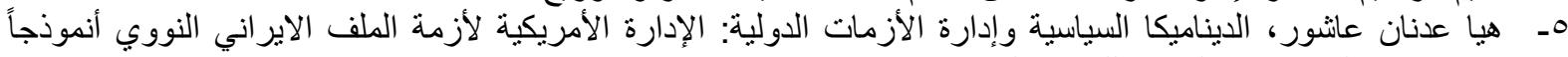

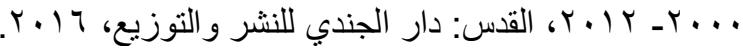

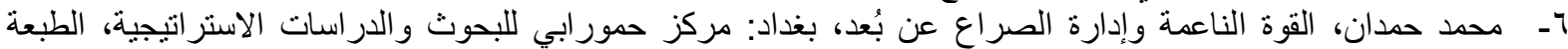

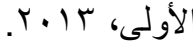
V- عزمي بشارة، سورية درب الآلام نحو الحرية_محاولة في التاريخ الراهن، الدوحة: المركز العربي للأبحاث و دراسات

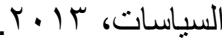

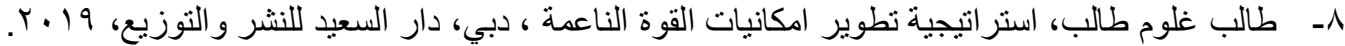
9- حسيب الدبدوي، اليابان ودبلوماسية القوة الناعمة : استر اتيجية المحيطين الهندي-الهادئ، منطقة حرة ومفتوحة، الرياض:

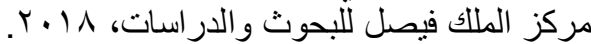

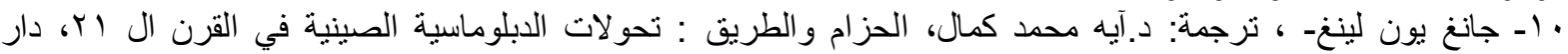

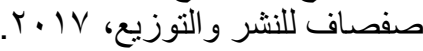

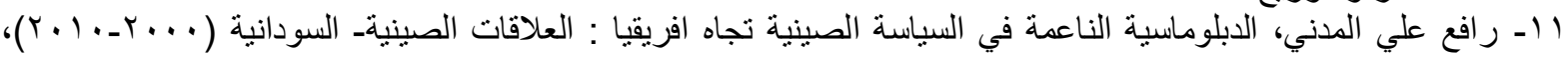

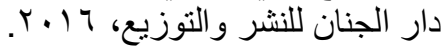




$$
\begin{aligned}
& \text { r ا ـ محمد و وائل القيسي، الأداء الأستراتيجي الأمريكي بعد العام ^ . . ץ: إدارة بار الك أوباما أنموذجاً، الرياض: العبيكان للنشر }
\end{aligned}
$$

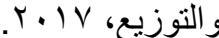

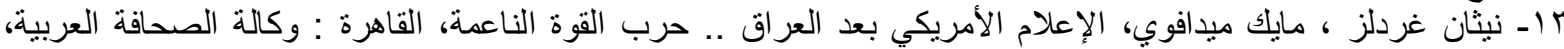

$$
\begin{aligned}
& r+1 \mathrm{~V}
\end{aligned}
$$

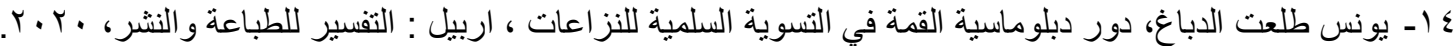

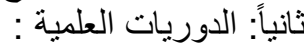

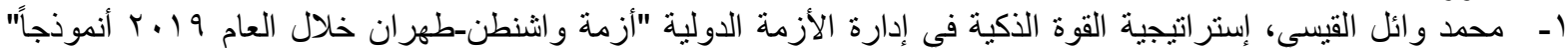

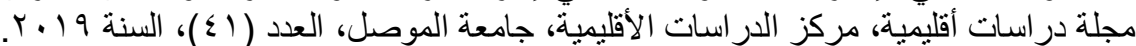

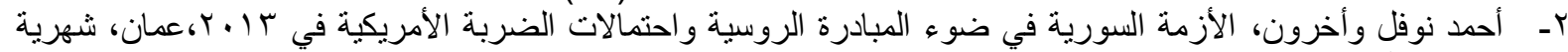

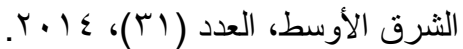

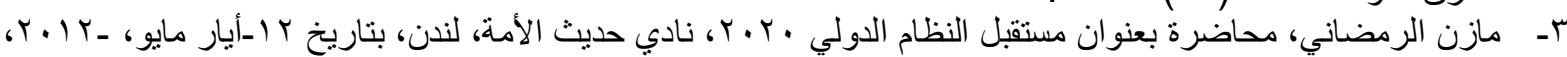

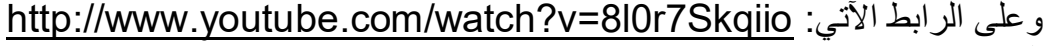

$$
\begin{aligned}
& \text { نالثاً: المصادر الاجنبية: }
\end{aligned}
$$

1- Chester Alexis C. Buama, Crisis Communication and Crisis Management, Society Publishing,2018.

2- Joseph S.Nye,The future of power, New york, Public Affairs,2011.

3- Hongyi Lai، Yiyi Lu,China's Soft Power and International Relations, Routledge, 2012.

4- Emilian Kavalski, Asian Thought on China's Changing International Relations, Springer, 2014 .

5- Lukas K. Danner, China's Grand Strategy: Contradictory Foreign Policy?,USA: Florida International University,2018.

6- Anders Corr, Great Powers, Grand Strategies: The New Game in the South China Sea, Naval Institute Press,2018.

7- Marc Lanteigne, Chinese Foreign Policy: An Introduction, London: Routledge, 2013.

8- Fareed Zakaria, The post American world, New york, 2008.

9- Carol Atkinson, Military Soft Power: Public Diplomacy through Military Educational Exchanges,UK,Rowman littlefield,2014.

10- Mingjiang Li,Soft Power: China's Emerging Strategy in International Politics, New york, Lexington Books.2009.

11- Lara Seligman, The Unintended Consequences of Trump's Decision to Withdraw From Syria, Foreign Policy, January 28,2019,On website :

https://foreignpolicy.com/2019/01/28/unintended-consequences-trump-decision-withdrawsyria/

12- Jonathan Stevenson, American Foreign Policy Is Broken. Suleimani's Killing Proves It, New york Times, Jan.4,2020,On website:

https://www.nytimes.com/2020/01/04/opinion/trump-soleimani-strike.html

13- -China sends doctors and masks overseas as domestic coronavirus infections drop, Mars, The Guradian,19,2020, on the website :

https://www.theguardian.com/world/2020/mar/19/china-positions-itself-as-a-leader-intackling-the-coronavirus

Abstract
The soft power strategy is the best mechanism for settling international crises in today's most developed world, because it depends on the diplomatic tools to settle disputes, and its adoption by international powers influencing international politics facilitates the possibility of achieving its strategic goals in a manner away from solid power, and increases The acceptance of other countries to it, as is the case with the soft American power toward Syria and Iran, as well as China's soft policy and its impact on China's global position and role.

Keywords: The soft power, international crises, diplomatic tools. 